\title{
Annals of Medicine
}

\section{Lipid Lowering Drugs and Inflammatory Changes: an Impact on Cardiovascular Outcomes?}

\author{
M. Ruscica, N. Ferri, C. Macchi, A. Corsini \& C. R. Sirtori
}

To cite this article: M. Ruscica, N. Ferri, C. Macchi, A. Corsini \& C. R. Sirtori (2018): Lipid Lowering Drugs and Inflammatory Changes: an Impact on Cardiovascular Outcomes?, Annals of Medicine, DOI: 10.1080/07853890.2018.1498118

To link to this article: https://doi.org/10.1080/07853890.2018.1498118

Accepted author version posted online: 06 Jul 2018.

Submit your article to this journal ¿

View Crossmark data $₫$ 


\title{
LIPID LOWERING DRUGS AND INFLAMMATORY CHANGES: AN IMPACT ON CARDIOVASCULAR
} OUTCOMES?

M. Ruscica ${ }^{1^{*}}$, N. Ferri ${ }^{2^{*}}$, C. Macchi $^{1}$, A. Corsini ${ }^{1}$ and C. R. Sirtori ${ }^{3}$

${ }^{1}$ Dipartimento di Scienze Farmacologiche e Biomolecolari, Università degli Studi di Milano, Milan, Italy; ${ }^{2}$ Dipartimento di Scienze del Farmaco, Università degli Studi di Padova, Padova, Italy; ${ }^{3}$ Centro Dislipidemie, A.S.S.T. Grande Ospedale Metropolitano Niguarda, Milan, Italy *Both authors contributed equally to this work

Corresponding Author:

Cesare R. Sirtori

cesare.sirtori@icloud.com

\begin{abstract}
Inflammatory changes are responsible for maintenance of the atherosclerotic process and may underlie some of the most feared vascular complications. Among the multiple mechanisms of inflammation, the arterial deposition of lipids and particularly of cholesterol crystals is the one responsible for activation of inflammasome NLRP3, followed by the rise of circulating markers, mainly C-reactive protein (CRP). Elevation of lipoproteins, LDL but also VLDL and remnants, associates with increased inflammatory changes and coronary risk. Lipid lowering medications can reduce cholesterolemia and CRP: patients with elevations of both are at greatest cardiovascular (CV) risk and receive maximum benefit from therapy. Evaluation of the major drug series indicates that statins exert the largest LDL and CRP reduction, accompanied by reduced CV events. Other drugs, mainly active on the triglyceride/HDL axis, e.g. PPAR agonists, may improve CRP and the lipid pattern, especially in patients with metabolic syndrome. The newest most potent medications, i.e. PCSK9 antagonists, do not induce significant changes in inflammatory markers, but patients with the highest baseline CRP levels show the best CV risk reduction. Parallel evaluation of lipids and inflammatory changes clearly indicates a significant link, both guiding to patients at highest risk, and to the best pharmacological approach.
\end{abstract}

Keywords: ezetimibe, CRP, Fibrates, LDL-C, PCSK9, statin 


\section{Key messages:}

1. Lipid lowering agents with "pleiotropic" effects provide a more effective approach to CV prevention

2. In CANTOS study, patients achieving on-treatment hsCRP concentrations $\leq 2 \mathrm{mg} / \mathrm{L}$ had a higher benefit in terms of reduction in major CV events

3. The anti-inflammatory activity of PCSK9 antagonists appears to be of a minimal extent 


\section{Introduction}

Inflammation has long been associated with the initiation and progression of atherosclerosis (1). Detection of elevated high sensitivity C-reactive protein (hSCRP) in sera of statin treated post-myocardial infarction patients with "residual inflammatory risk" (2), opened up a new front in the evaluation and treatment of patients with a high risk of recurrent events (3). The initial observations in patients with relatively normal lipoprotein levels and positively responding to statins, in the presence of isolated hsCRP elevations, gave the first demonstration of the validity of this approach in a number of clinical studies (4). Insights into the role of inflammation in the pathogenesis of atherosclerosis came also from a meta-analysis of 54 long-term prospective studies, comprehensive of 160,309 people without a history of vascular disease, reporting a continuous association of hSCRP levels with the risk of coronary heart disease, ischemic stroke and vascular mortality. The ability of hsCRP to predict risk is as large as that of cholesterol and blood pressure (5). When evaluating 23 studies in a metaanalysis on 57 patient groups treated with different hypocholesterolemic agents (statins and non-statins) Kinlay reported a strong correlation between LDL-C reduction and lowering of hsCRP, confirming the concept of LDL-C lowering as a determinant for the reduction in inflammation, possibly contributing to lower CV risk (6) (Figure 1).

The present review article is aimed at evaluating the present-day status of the clinical approach to patients with an elevated CV risk. This initial evaluation will allow to better define a therapeutic approach. It has, in fact, been clearly reported in recent years that even after optimal treatment of patients with manifest vascular disease, the rate of recurrent events can be relatively high. These data suggest that even when all target values have been reached, many such patients will maintain a $>20 \%$ or even $>30 \% \mathrm{CV}$ risk over 10 years and thus an area of substantial medical need is clearly present (7).

\section{Lipoproteins and CV risk}

In the development of vascular atheroma, in the presence or absence of inflammatory changes, lipoproteins still play a major role.

\subsection{Low-density lipoproteins.}

Low-density lipoproteins (LDL) represent the most significant accompanying biochemical variable associated with atheroma. The association between lowering of LDL-C and cardiovascular risk reduction was evaluated by Silverman across different statin and non-statin 
therapies. The relative risk of major vascular events was similar for all drug classes (statins, bile acid sequestrants, ezetimibe, and fibrates), and the lower achieved LDL C levels (not percentage reductions) were associated with a reduced incidence of major CV events (8). As recently reported in a meta-analysis and meta-regression analysis of 34 primary and secondary prevention trials of intensive (136,299 patients) vs less intensive (133,989 patients) LDL lowering therapy (statins, ezetimibe and PCSK9 inhibitors) clear differences were detected in patients who benefitted most from LDL lowering. In terms of risk reduction of total and CV mortality, myocardial infarction (MI), revascularization, and major adverse cardiac events (MACE), patients with baseline $L D L-C \geq 100 \mathrm{mg} / \mathrm{dL}$ and receiving the more intensive treatment had the greatest benefit $(9,10)$.

A number of studies indicate that elevations of LDL-C are associated with the presence of vascular atheromas, both as witnessed by increased vascular events as well as by the reduction of events in the presence of cholesterol lowering medications (11). In these conditions the presence of a vascular inflammatory pattern can be explained by a number of mechanisms, the most significant being a local inflammatory stimulus exerted by the cholesterol crystals, potentially a trigger of the perforation of the fibrous cap (12). Cholesterol crystal formation is due to an imbalance between esterified and free cholesterol as well as by changes in HDL function (13), involved in the reverse cholesterol transport process (14). Monocytes and macrophages avidly phagocytose cholesterol crystals increasing secretion of IL$1 \beta$ through activation of the inflammasome NLRP3 (15). The NOD-like receptor pyrine domaincontaining protein 3, i.e. NLRP3, in phagocytes, leads in fact to phagolysosomal damage (16). Reduction of cholesterolemia, e.g. by drugs, will lead to reduced cholesterol crystal formation and, as a consequence, to reduced atheromas. Whether reduction of the inflammatory potential of macrophages may occur in the absence of NLRP3 activation remains an important question (13). It may indicate an additional pathway to that of cholesterol reduction, since other lipids and lipoproteins may also a carry significant risk of both atheromas and inflammatory changes.

Elevated LDL thus carry a pleiotropic risk, being associated to increased generalized inflammation and, because of a stimulated cellular immunity, essentially on T cells during all stages of disease, exerting a major role in the initiation, progression and rupture of plaques. In the T-cell population of human plaques, CD4+ dominate over CD8+ cells with CD4+ clones responding to components of oxidized LDL (17); proinflammatory T helper (Th)-1 lymphocytes 
aggravate atherogenesis with Th2 and Th17 further influencing lesion composition; conversely, regulatory $T$ cells mitigate this process (18).

In addition to effects elicited through inflammatory mediators, very recently a reduced expression of the epigenetic modifier enzyme ten-eleven translocation 2 (TET2), promoting expansion of clonal hematopoiesis, has been found to raise the atherosclerotic risk (19). TET2 mutant cells leading to TET2 deficiency, when clonally expanded in the bone marrow, markedly increase the atherosclerotic plaque size; TET2 deficient macrophages, in addition, increase the NLRP-3 inflammasome mediated IL-1ß secretion. This model has allowed to note that the NLRP3 inhibitor, MC950, can suppress IL-1ß secretion in hyperlipidemic animal models, thus supporting a major role of TET2 deficiency (20).

LDL-associated inflammatory changes have thus at least a three-pronged determination: 1) increased LDL associates with extensive tissue inflammatory changes, mainly linked to increased hsCRP; 2) The rise of different $T$ lymphocyte subtypes may lead to plaque proliferation and potentially rupture; 3) cholesterol crystal deposition, leading to a rise of the vascular inflammasome NLRP3, that may accelerate atherosclerosis development particularly in the presence of mutations of the epigenetic modifier enzyme TET2 $(19,20)$.

\subsection{Elevation of triglycerides (TG) in very low-density lipoproteins (VLDL)}

The inflammatory potential of VLDL is best detected in the postprandial state. Evaluation of postprandial (PP) TG-rich lipoproteins from normal to a hypertriglyceridemic condition has indicated a raised inflammatory response, particularly when PP-VLDL are combined with low dose TNF- $\alpha$ as in the frequent case of elevated waist circumference (21). From these basic observations, clearly indicative of the inflammatory potential activity of VLDL and particularly PP-VLDL, the general agreement has been reached that the VLDL particles occurring in PP condition, so-called "remnant VLDL" (i.e. particles not completely catabolized by the lipoprotein lipase enzyme) can be responsible for both low-grade inflammation and for ischemic heart disease (22). These authors, in particular, reported the association of $38.7 \mathrm{mg} / \mathrm{dL}$ higher levels of non-fasting remnant cholesterol with 37\% higher hsCRP levels. By a logistic regression analysis of their population studies (Copenhagen General Population Study and Copenhagen City Heart Study) a $38.7 \mathrm{mg} / \mathrm{dl}$ elevation of non-fasting remnant cholesterol was associated with a causal risk ratio for ischemic heart disease of $3.3(95 \% \mathrm{Cl}, 2.1-5.2)$ vs $1.8(95 \% \mathrm{Cl}, 2.1-5.2)$ for elevated LDL-C. 
It should be also reported that elevated plasma TG levels are identified as independent predictors of CVD risk even in patients who have achieved LDL-C treatment goals with statin therapy (23). While elevated TGs do not exert an inflammatory stimulus per se, endothelial damage may occur, also because of the occurrence of intravascular TGs hydrolysis via the activity of lipoprotein lipase either at the endothelial surface or within the arterial intima. This process leads to a release of free fatty acids and monoacylglycerols which generate local inflammation (24). A meta-regression analysis of the effects of TG-lowering in fibrate trials showed that a $9 \mathrm{mg} / \mathrm{dL}$ decrease in TGs reduced coronary events by $5 \%$, the largest risk reduction occurring in those with baseline TGs of at least $177 \mathrm{mg} / \mathrm{dL}(25)$. In these, a $89 \mathrm{mg} / \mathrm{dL}$ drop in TGs associates with a $-54 \%$ reduction in coronary events (7).

\subsection{Elevation of lipoprotein(a)}

This lipoprotein is still a disputed cause of myocardial infarction, atherosclerotic coronary and aortic valve stenoses (26). Elevated $L p(a)$ levels may not be necessarily associated with the development of disease, whereas a number of additional genetic variables, i.e. in particular small sized $L p(a)$, are best associated with the clinical consequences of $L p(a)$ elevations, in particular aortic valve calcification (27). The presence in $L p(a)$ of a cholesterol-rich LDL particle covalently bound to an apo (a) glycoprotein (28), allows, in fact, the transfer of associated cholesterol to the aortic valves, and, in addition, to other vascular atheromatous changes (29).

Concentrations of $L p(a)$ are influenced by the apo(a) kringle IV2 repeat isoforms (30). Very recently a genome wide association metaanalysis adjusted for $L p(a)$ concentrations and apo (a) isoforms, reported a SNP increasing allele ( $r$ 186696265) both raising Lp(a) and increasing CAD risk (odds ratio 1.73). The apo E2 allele was also found to be a strong determinant of $L p(a)$ concentrations: each apo E2 allele can decrease $L p(a)$ by $3.34 \mathrm{mg} / \mathrm{dL}$ (31). Most interestingly, by performing a gene-based test-association study, a significant association of the TLR2 gene with $\operatorname{Lp}(\mathrm{a})$ was detected. Interestingly, all these genes both associate with raised CV risk and with tissue changes linked to inflammation. In mice, in fact, TLR2 activation was shown to result in a 14-fold increase in PCSK9 expression (32).

These findings gained particular significance after the recent observation that the frequent splice variant G4925A associates with the smaller LP(a) isoforms, generally leading to enhanced cardiovascular risk (33). Surprisingly this variant does not lead to increased but rather to reduced CV risk from 1.39 (95\% Cl 1.17 and 1.66 for wild type LMW individuals) to 1.19 for carriers of this variant. This further observation of anomalous genetic influences on $L p(a)$ and 
CV risk need as yet to be clarified by possible links with inflammatory changes due to competition between $\mathrm{Lp}(\mathrm{a})$ and plasminogen, thereby antagonizing the role of plasmin in dissolving fibrin clots and the associated inflammatory changes (34).

Elevated $\mathrm{Lp}(\mathrm{a})$ finally associates with oxidized phospholipids (OxPL) on apolipoprotein B100 (OxPL-apo B) (35). The highest tertiles of both $L p(a)$ and OxPL-apoB are independent predictors of more rapid aortic stenosis progression and also of generalized arterial disease (36).

\subsection{High density lipoproteins}

On the opposite side of these rated as atherogenic lipoproteins are high density lipoproteins (HDL). These are definitely associated with both a reduction in CV risk and lesser inflammatory changes. Calabresi et al. first outlined the mechanism whereby HDL may reduce arterial contractility and activation of platelet binding sites, improving endothelial function. Raised endothelial signaling molecules, in addition, can activate guanylate cyclase in vascular smooth muscle cells (37). Endothelial dysfunction is a consequence of an endothelial damage: injured vascular endothelial cells induce the expression of cell adhesion molecules (CAMs) by downregulation of TNF- $\alpha$-induced CAM expression and reduced IL-6 production (38).

In animal models of atherosclerosis, overexpression of apoAl in apoE-deficient mice significantly reduces CAM expression on vascular endothelial and the consequent monocyte recruitment into be arterial wall (39). These vascular effects of HDL are of course associated to their direct effect on cholesterol removal from tissues, still rated as the most valid mechanistic approach to vascular disease reduction (40). Very recently, changes in coronary plaque lipid burden, as assessed by near infrared spectroscopy, were found to be associated with even a modest elevation in HDL-Clevels in man (41), thus underlining the role of these lipoproteins in reducing atheroma formation. A final mediator of HDL function is symmetric dimethylarginine (SDMA), a still not completely understood mediator of nitric oxide (NO) synthesis. Very recently (42) Zewinger et al reported that the association of SDMA with HDL leads to higher mortality, because of a reduction of the anti-inflammatory and regenerative properties of HDL.

\section{Inflammatory markers; CV risk associated to inflammatory markers and their correction}

\section{(CANTOS Study)}

Recently, perplexities have been raised on the actual biomarker role of CRP, after a study on genetic loci associated with hsCRP levels failed to detect a clear link between these and the the 
occurrence of CV events, in contrast to neighboring loci such as $I L-6 R$ or the APOCI-CII gene cluster (43). A later Mendelian randomization study (44) from a coronary heart disease genetic collaboration, investigated individuals from 47 epidemiological studies in 15 countries and detected four genes tagging single nucleotide polymorphisms in the CRP gene. Variants of these genes were associated to an up to $30 \%$ per allele difference in hsCRP concentrations but were unrelated to other coronary risk factors. None of these alleles appeared to be additive to the classical risk scores for coronary heart disease.

In spite of the altogether not informative genetic characterization, the results of the very recent CANTOS (Canakinumab Anti-Inflammatory Thrombosis Outcome Study) trial have undoubtedly shed light on the role of inflammation in atherosclerosis development. Canakinumab is a human monoclonal antibody against interleukin-1 $\beta$, approved for clinical use after a 48-week randomized placebo-controlled trial involving 35 patients with cryopyrinassociated periodic syndrome (CAPS), a spectrum of autoimmune inflammatory syndromes. Subcutaneous administration of $150 \mathrm{mg}$ canakinumab at two-monthly intervals led to a rapid remission of symptoms in most patients; CRP levels dropped from a baseline of $20 \mathrm{mg} / \mathrm{L}$ to 2.1 $\mathrm{mg} / \mathrm{L}$ at the end of the study (45).

Canakinumab was generated by using transgenic mice, immunized with a recombinant form of human IL-1 $\beta$, producing multiple high-affinity human IgG1/k isotype mAbs (46). The relative molecular mass of canakinumab, based on the amino acid composition without posttranslational glycosylation, but including $\mathrm{N}$-terminal pyroglutamate formation and the $\mathrm{C}$ terminal lysine residues at the heavy chains, is $145.16 \mathrm{kDa}$ (47). Canakinumab binds to human IL-1 $\beta$ with high affinity and a dissociation equilibrium constant of approximately 35-40 pM (48). It is eliminated by intracellular catabolism following a fluid-phase or receptor-mediated endocytosis (49). Interestingly, although the epitope appears to be outside the IL-1ß/IL1receptor interface, the IL-1 $\beta$ complexed with canakinumab does not attach to the cell surface receptor, thus avoiding the IL-1 $\beta$-dependent signaling.

In healthy volunteers, canakinumab shows a volume of distribution ( $\mathrm{Vd}$ ) of $5.4 \mathrm{~L}$ and a terminal half-life of 33 days. Administration of 1,3 and $10 \mathrm{mg} / \mathrm{kg}$ canakinumab leads to a $\mathrm{C}_{\max }$ of $1.2,1.2$ and $1.5 \mathrm{pM}$, respectively, 42 to 56 days after the first infusion. In CAPS patients, with $70 \mathrm{~kg}$ mean body weight, administration of $150 \mathrm{mg}$ canakinumab led to a $\mathrm{C}_{\max }$ of $16 \pm 3.5 \mu \mathrm{g} / \mathrm{mL}$ with a half-life of 26 days and $V d$ of $6.1 \mathrm{~L}(47,48)$. In patients with systematic juvenile idiopathic arthritis (another therapeutic indication) clearance and $\mathrm{Vd}$ were $0.106 \mathrm{~L} /$ day and $3.2 \mathrm{~L}$, respectively, for a body weight of $33 \mathrm{Kg}$, with an estimated half-life of 22 days (50). 
Interleukin-1 $\beta$ is a major cytokine promoting inflammation in atherosclerosis. IL-1 $\beta$ belongs to a family of 11 cytokines mediating expression of numerous genes involved in the immune response during infection and inflammation. Pro-IL-1 $\beta$ undergoes proteolytic cleavage to produce mature IL-1 $\beta$ possessing biological activity. The activation of IL-1 $\beta$ begets many molecules of IL-6 leading to the overexpression of atherothrombosis mediators (51).

The CANTOS trial, representing a proof-of-concept for the residual inflammatory risk hypothesis, enrolled 10,061 patients with a previous myocardial infarction and hsCRP $\geq 2 \mathrm{mg} /$. Patients were randomly assigned to receive, once every 3 months, canakinumab s.c. at the doses of $50 \mathrm{mg}, 150 \mathrm{mg}$ and $300 \mathrm{mg}$. Being $>90 \%$ of the studied population on statins, LDL-C levels were around $80 \mathrm{mg} / \mathrm{dl} ; 80 \%$ had previously undergone coronary revascularization (52). After a median follow-up of 3.7 years, only the dose of $150 \mathrm{mg}$ led to a significant reduction of the primary endpoint, i.e. a composite of nonfatal MI, any nonfatal stroke, or CV death (52). The hazard ratio $(\mathrm{HR})$ for the primary endpoint was $0.85,95 \% \mathrm{Cl}: 0.74-0.98, \mathrm{p}=0.021$, with a number-needed to treat (NNT)) of 156 during 1 year to prevent an event. Most of the antiatherothrombotic effects are ascribable to the reduction of MI in 1 year (HR: 0.76) with a NNT of 189 (53); CV deaths were not significantly reduced (HR: 0.88). Addition of urgent revascularization for unstable angina to the components of the primary endpoint led to a more robust statistical significance, namely a $-17 \%$ decrement (HR: $0.83 ; 95 \% \mathrm{Cl}: 0.73-0.95$ ) in major adverse cardiac events (MACE), i.e. $-24 \%$ MIs (HR: 0.76 ; $95 \% \mathrm{Cl}: 0.62-0.92$ ) and $-37 \%$ urgent revascularizations (HR: $0.64 ; 95 \% \mathrm{Cl}: 0.44-0.94)(52)$. These findings may be consequent to a disproportionate benefit in patients experiencing partially occlusive events, i.e. non-STsegment-elevation $\mathrm{MI}$ and unstable angina (54). Hence, a better understanding of the clinical features of MIs (infarct size, Q-wave vs. non-Q-wave and spontaneous or procedure-related) will help to assess the definite clinical benefit of canakinumab (55). By the end of the CANTOS Study, canakinumab reduced hsCRP by $35 \%$ without affecting, at any dose, LDL-C (Figure 1), HDL-C and TG levels (56) (Table 1). No reduction in the incidence of new-onset diabetes (HR $1.02,95 \% \mathrm{Cl} 0.87-1.19)$ was found with a similar effect of canakinumab in reducing MACE rates in patients with or without diabetes $(57,58)$.

Interestingly, a secondary analysis showed that, among patients allocated to canakinumab, those achieving on-treatment hsCRP concentrations $\leq 2 \mathrm{mg} / \mathrm{L}$ had a higher benefit in terms of reduction in major CV events (HR: 0.75; 95\% Cl: 0.66-0.85, $\mathrm{p}<0.001$ ), cardiovascular mortality (HR: $0.69 ; 95 \% \mathrm{Cl}: 0.56-0.85, \mathrm{p}=0.0004$ ) and all-cause mortality (HR: $0.69 ; 95 \% \mathrm{Cl}: 0.58-0.81, \mathrm{p}<0.001$; Figure 2). Relative to the key prespecified secondary 
endpoints (non-fatal MI, non-fatal stroke, hospitalization for unstable angina requiring unplanned revascularization, or cardiovascular death), a $26 \%$ risk reduction was observed among participants treated with any dose of canakinumab who achieved hsCRP levels $<2 \mathrm{mg} / \mathrm{L}$, (HR: $0.74 ; 95 \% \mathrm{Cl}: 0.65-0.83 ; \mathrm{P}<0.0001)(56,59)$. The benefit in reaching this hsCRP threshold is translated into a 5-year NNT estimate for MI, stroke, coronary revascularization, or death from any cause of 16 . Conversely, for those participants who did not achieve on-treatment hsCRP < $2 \mathrm{mg} / \mathrm{dL}$ the 5 year NNT estimate was $57(56,59)$.

Relative to safety concerns, although no increments in all-cause mortality and newonset diabetes were found $(52,57)$, when data from the three doses of canakinumab were pooled, the number of deaths from infection was significantly higher in patients on canakinumab vs placebo (55).

\section{Effects of Lipid Lowering agents on Inflammation}

\subsection{Statins}

The 3-hydroxy-3-methylglutaryl (HMG)-CoA reductase inhibitors (statins), can achieve a large reduction of plasma cholesterol and coronary artery disease (CAD). Statins inhibit the biosynthesis of cellular cholesterol in the liver, thus resulting in an increased expression of the LDL receptor and uptake of LDL cholesterol from the circulation. A meta-analysis from the Cholesterol Treatment Trialists' (CTT) Collaboration from 90,000 individuals in 14 randomized trials of statin therapy, demonstrated a weighted mean difference of about $1.0 \mathrm{mmol} / \mathrm{L}$ in LDL cholesterol and a proportional reduction of (about 20\%) of major vascular events (defined as coronary death, non-fatal myocardial infarction, coronary revascularization, or stroke) (60).

At the pharmacokinetic level (i.e., absorption, distribution, metabolism, and excretion of a given drug) available statins display important differences, including half-life, systemic exposure, maximum plasma concentration $\left(C_{\max }\right)$, bioavailability, protein binding, lipophilicity, metabolism, presence of active metabolites, and excretion routes (61).

It is usually assumed that any beneficial effect of statins on coronary events is linked to their hypocholesterolemic properties. However, because mevalonic acid, intracellularly synthesized by HMG-CoA reductase, is the precursor of numerous metabolites, inhibition of HMG-CoA reductase has the potential to result in pleiotropic effects $(62,63)$; hence, effects other than cholesterol reduction may help explain the anti-atherosclerotic properties of statins, such as improvement of endothelial function and reduction of platelet aggregation, increased number and activity of endothelial progenitor cells, inhibition of migration and 
proliferation of smooth muscle cells, stabilization of coronary plaques and atheroma regression (64-66).

Among all these pleiotropic effects, statins were shown to reduce CRP levels, and for this reason to exhibit anti-inflammatory properties. However, statins, by reducing LDL-C levels, decrease the number of LDL particles, that can infiltrate vessel walls, thus limiting atherosclerosis progression and local inflammation. The reduction of CRP could be thus related to the lipid lowering effect of statins. The mutual relationship between inflammation and lipid metabolism is also dictated by the fact that pro-inflammatory cytokines regulate the transcription of many genes involved in cholesterol and TG synthesis $(67,68)$.

The first study showing a lowering effect of statins on hSCRP was the CARE (Cholesterol and Recurrent Events) trial. This study showed that the relative CV risk reduction attributable to statin treatment was larger in patients with elevated hsCRP (69). This observation was subsequently confirmed in other studies, such as the Air Force/Texas Coronary Atherosclerosis Prevention Study (AFCAPS/TexCAPS), REVERSAL (Reversal of Atherosclerosis with Aggressive Lipid Lowering), PROVE IT-TIMI 22 (Pravastatin or Atorvastatin Evaluation and Infection Therapy-Thrombolysis in Myocardial Infarction 22) and A to Z (Aggrastat-to-Zocor) $(2,70-72)$ (Table 1). All these led to hypothesize a dual goal for an antiatherosclerotic therapy, the largest clinical benefit being found in patients not only achieving LDL-C below $70 \mathrm{mg} / \mathrm{dL}$ but also hsCRP below $2 \mathrm{mg} / \mathrm{L}$ (73). This concept was then confirmed in the primary prevention JUPITER trial on 18,000 patients with median LDL-C of $108 \mathrm{mg} / \mathrm{dL}$ and elevated hsCRP (>2.0 mg/L) (74). Rosuvastatin $20 \mathrm{mg}$ reduced by half the rate of major CV events such as stroke, nonfatal myocardial infarction, revascularization, unstable angina or death from CV causes (74), thus supporting the conclusion that on-treatment levels of hSCRP are as important for predicting recurrent disease as on treatment levels of LDL-C. Furthermore, the largest reduction in CV events (-65\%), occurred in patients achieving both LDL-C $<70 \mathrm{mg} / \mathrm{dL}$ and $\mathrm{hsCRP}<2 \mathrm{mg} / \mathrm{dL}$ compared to those achieving only one of the two targets (-33\%) (75).

In the MIRACL (The Myocardial Ischemia Reduction with Acute Cholesterol Lowering) and REVERSAL trials, the effect of statins on CRP was shown to be dose dependent, with a higher reduction after more aggressive therapy (atorvastatin) compared to standard therapy (pravastatin) $(6,76)$ (Table 1$)$.

In addition to the effects of statins on hsCRP and systemic inflammation, some clinical evidence has suggested that statins can ameliorate the vascular inflammatory status, in 
particular improving endothelial function in patients with cardiovascular risk or $\operatorname{CAD}(77,78)$, with a well-defined timing and potency related effect (79).

While there is no doubt that statins can improve systemic inflammation (reduction of hs(RP), whether this action is related to their lipid lowering properties is still a matter of discussion $(43,44,80)$. The effects of statins on hsCRP are likely to be related to a general positive effect on other atherogenic players that determine the final anti-inflammatory action, and statins may elicit their pleiotropic effects independent of their lipid lowering activity. Thus, the reduction of LDL-C levels with a mechanism not involving HMG-CoA reductase, could certainly help to better define the relationship between hsCRP and LDL-C and to potentially clarify the direct benefit of hsCRP reduction on cardiovascular disease.

Statins thus display significant anti-inflammatory effects, also leading to some non-lipid indications, e.g. for the treatment of periodontal inflammation (81), where periodontal responses were associated with changes in carotid inflammation. Reduction of hSCRP appears to be related to LDL-C lowering and may be an important determinant of CV risk reduction (Figure 1).

\subsection{Ezetimibe}

Ezetimibe is an inhibitor of the cholesterol transport protein NPC1-like 1 and reduces intestinal cholesterol absorption (82). When added to statin therapy, ezetimibe resulted in incremental lowering of LDL-C levels and improved cardiovascular outcomes ( $2 \%$ reduction of absolute risk) (83).

Following oral administration, ezetimibe is rapidly glucuronidated in the intestines and the glucuronide undergoes enterohepatic recirculation which explains the long duration of action accounting for a half-life of $22 \mathrm{~h}$ (84). Ezetimibe does not interact with drugs metabolized by CYP450 1A2, 2D6, 2C8, 2C9, or 3A4, and, in particular, does not interact with statins.

In an experimental study on rabbits on a high fat diet and femoral atherosclerosis, ezetimibe treatment was associated with both reduced atheroma progressions and plaque stabilization: CRP levels were significantly reduced with no further reduction by the addition of simvastatin (85). Somewhat divergent data have been provided by the clinical studies: the majority of these have been, in fact, conducted in combination with statins and a small number as monotherapy. A pooled analysis of randomized, placebo-controlled trials of ezetimibe 10 $\mathrm{mg} /$ day in patients with hypercholesterolemia, showed no significant difference on hsCRP levels ( $+5 \%$ and $-1 \%$ for placebo and ezetimibe group, respectively). On the contrary, when 
ezetimibe was added to baseline statin therapy a $-10 \%$ reduction of hsCRP was observed (-1\% vs $-12 \%$ for placebo plus statin and ezetimibe plus statin, respectively) (86). A very similar effect was observed in the IMPROVE-IT trial, where the addition of ezetimibe to simvastatin therapy resulted in a further $-20 \%$ reduction of LDL-C and a $-14 \%(0.3 \mathrm{mg} / \mathrm{L})$ reduction of hsCRP (87). This translated into significantly more patients meeting both of the prespecified targets of LDL$\mathrm{C}<70 \mathrm{mg} / \mathrm{dL}$ and $\mathrm{hsCRP}<2 \mathrm{mg} / \mathrm{L}$ in the ezetimibe/simvastatin group compared to simvastatin alone (-50\% vs $-29 \%$ ) (87). Again, in the SHARP trial, that recruited patients with chronic kidney disease, the combination simvastatin/ezetimibe produced a $-35 \%$ reduction of LDL-C vs placebo and a $-21 \%$ reduction of hsCRP (88) (Table 1 ).

A number of studies have investigated statin therapy versus statins in combination with ezetimibe on endothelial function as a measure of vascular inflammation (77, 89-96). Results were found to be inconstant: six studies found no difference in endothelial function $(89,91,94$, 96-98), four found statin alone be better (77, 92-94), and one study found a beneficial effect of combination therapy over statin alone (90). However, in many of these studies comparing statins vs combination therapy, markedly different lipid lowering effects were found, thus making comparisons difficult $(77,89-91,94)$. Two cross-over studies with a reduced risk of confounding and bias, reached discordant conclusions, one showing an improved endothelial function on statin alone (93), and the other not observing any significant difference between the two treatments (97).

Ezetimibe can thus provide an additive effect to that of statins both on LDL-C and on hsCRP-lowering (Figure 1). The mechanism of this latter effect is not fully clarified.

\subsection{Fibrates}

Fibrates are activators of the peroxisome proliferator-activated receptor (PPAR) system, mainly PPAR- $\alpha$, and have shown a significant benefit in clinical trials of CV prevention, i.e. reducing the occurrence of nonfatal $\mathrm{MI}$, particularly when restricting evaluation to patients with concomitant TG elevation and HDL-C reduction $(99,100)$. In this context, results from the longterm (10 years) extension of the ACCORD (Action to Control Cardiovascular Risk in Diabetes) trial confirmed the significant preventive benefit of fenofibrate in patients with combined elevation of TG and reduction of HDL-C levels (101).

Fenofibrate is rapidly hydrolysed after absorption, to fenofibric acid, the major active metabolite. The drug is excreted unchanged in urines either as fenofibric acid or as its 
glucuronide conjugate. No hepatic microsomal metabolism is involved, not being fenofibric acid a substrate for CYP3A4 (102).

A recent meta-analysis evaluated hsCRP changes after fibrates and reported that these are correlated with HDL-C rises, in particular a mean $1 \%$ elevation in HDL corresponding to a 2.03\% decrement in hsCRP (103). Administration of fibrates led to a significant overall mean hsCRP reduction of $-0.47 \mathrm{mg} / \mathrm{L}(95 \% \mathrm{Cl}:-0.93,-0.01)$, mainly ascribable to trials recruiting patients with baseline CRP $\geq 3 \mathrm{mg} / \mathrm{L}(-1.01 \mathrm{mg} / \mathrm{L} ; 95 \% \mathrm{Cl}:-1.86,-0.16)$. The effect was lost when baseline hsCRP values were $\leq 3 \mathrm{mg} / \mathrm{L}(-0.25 \mathrm{mg} / \mathrm{dL} ; 95 \% \mathrm{Cl}:-0.74,0.25 ; \mathrm{p}=0.33)$. These findings were not fully confirmed by a sub-analysis of the FIELD (Fenofibrate Intervention and Event Lowering in Diabetes) trial, originally designed to assess the effect of fenofibrate on CV events in patients with type 2 diabetes (T2D) (104). In FIELD a 5-year treatment with fenofibrate significantly reduced LDL-C (14.2\%) but not hsCRP (+ $0.8 \mathrm{mg} / \mathrm{L})$. These findings did not differ when patients were stratified for the hsCRP cut-off of $2.0 \mathrm{mg} / \mathrm{L}$ (105) (Table 1).

In an attempt to reduce the residual CV risk in high-risk patients with mixed hyperlipidemia, e.g. in T2D, the addition of a fibrate to statin therapy has been suggested (106). However, although a fibrate-statin combination may reduce to a greater extent total cholesterol (-2.2\%; 95\% Cl: 1.9-2.5), LDL-C (-2.3\%; 95\% Cl: 2.0-2.5), and TGs (-0.4\%; 95\% Cl: 0.2-0.6) compared to statin alone, a higher risk of side effects (muscular and consequently renal) may occur with gemfibrozil, to a lesser extent with fenofibrate and bezafibrate $(61,107)$.

The DIACOR (Diabetes and Combined Lipid Therapy Regimen) trial directly evaluated a 12-week treatment with fenofibrate, simvastatin or their combination (fenofibrate $160 \mathrm{mg}$ and simvastatin $20 \mathrm{mg}$ ) in T2D patients with mixed dyslipidemia and no history of CV events. hsCRP levels were reduced by $-18.9 \%,-24.9 \%$ and $-27.3 \%$, respectively, but the combination therapy was not more effective than either fenofibrate or simvastatin alone (108) (Table 1). Similarly, no additional benefit of a combination therapy on hsCRP reduction was seen in patients with mixed dyslipidemia receiving rosuvastatin (40 mg), as monotherapy, or as an add-on therapy to fenofibrate (200 mg). Rosuvastatin monotherapy led to a $56 \%$ reduction in hsCRP vs baseline, whereas the combination with fenofibrate, unexpectedly, did not change hsCRP levels (109). Confirming prior studies, instead, in patients with mixed dyslipidemia, rosuvastatin (40 mg), rosuvastatin $(10 \mathrm{mg}$ ) plus fenofibrate $(200 \mathrm{mg}$ ) or rosuvastatin $(10 \mathrm{mg})$ plus omega 3 (2 g) resulted in a $-53 \%,-28 \%$ and $-23 \%$ reductions in hsCRP, respectively, vs baseline (110).

In the attempt to improve the lipid profile in patients in patients with mixed hyperlipidemia, characterized by both hypercholesterolemia and hypertriglyceridemia, fibrate 
co-administered with ezetimibe has been proposed. In a 48-week trial, enrolling 576 patients with LDL-C 130 to $220 \mathrm{mg} / \mathrm{dL}$ and TGs 200 to $500 \mathrm{mg} / \mathrm{dL}$, the co-administration of fibrate plus ezetimibe was more effective than fenofibrate alone in reducing LDL-C (-22\% vs $-8.7 \%)$, TGs (-46 $\%$ vs $-41.8 \%)$ and non-HDL-C (-31.6\% vs $-19.4 \%)$. Both treatments significantly reduced hsCRP vs baseline, with no further benefit of adding ezetimibe to fenofibrate $(-25.3 \%$ vs $-21.1 \%)(111)$ (Table 1).

Fibrates thus improve inflammatory changes in conditions of hyperlipidemia. Reduction of the major marker, hsCRP, appears to be related to the rise of HDL-C (98) and may be additive to the effects of statins and ezetimibe. No definitive data are available on the possible influence of this pleiotropic activity on the reduction of CV risk.

\subsection{Proprotein convertase subtilisin/kexin 9 (PCSK9) antagonists}

Proprotein convertase subtilisin/kexin 9 (PCSK9) is a liver-secreted plasma protein that, by a post-translational mechanism, regulates the number of cell-surface LDL receptors (LDL-R), thus inhibiting LDL uptake. Indeed, by binding to the epidermal growth factor-like repeat homology domain A of human LDL-R, PCSK9 has a dual effect (i) acting as a courier, facilitating the exit of LDL-R from the endoplasmic reticulum, and (ii) fostering the degradation of the LDL-R at the cell surface (112-114). Thus, in order to increase the number of LDL-R, inhibition of PCSK9 has been achieved by mean of monoclonal antibodies (mAbs). Two fully human IgG1 and IgG2 mAbs, alirocumab and evolocumab, respectively, have been approved in the United States and in the European Union in August 2015, whereas bococizumab, a humanized mAbs, has been discontinued in November $2016(115,116)$. Interestingly, other approaches to inhibit PCSK9 are being developed, i.e. antisense oligonucleotides, small-molecule inhibitors, and RNA interference therapies (inclisiran) (117) and a vaccine (118).

The pharmacokinetics of PCSK9 inhibitors is closely related to the biochemical characteristics of monoclonal antibodies. Absolute bioavailability is $72 \%$ for evolocumab and 85\% for alirocumab, with distribution volumes of 3.3 $\mathrm{L}$ and 3.0-3.8 L, respectively, confirming the limited tissue distribution of mAbs. Effective plasma half-lives are 11-17 days for evolocumab (119) and 17-20 days for alirocumab (120), reduced by statin co-administration. Indeed, evolocumab clearance is increased by about $20 \%$, partially due to the statin-driven upregulation of PCSK9. Similarly, alirocumab exposure was reduced by about $40 \%, 15 \%$, and $35 \%$ when administered with statins, ezetimibe, and fenofibrate, respectively (121). However, these drug-drug interactions are not to be rated as clinically meaningful and do not require 
dose adjustment. Proteolytic and target-mediated elimination pathways have been described: the first one prevails in the presence of high drug concentrations, whereas the second becomes prevalent at low concentrations.

So far, the Food and Drug Administration (FDA) and the European Medicines Agency (EMA) approved the use evolocumab for cholesterolemia reduction in the homozygous (HoFH) and heterozygous forms of familial hypercholesterolemia ( $\mathrm{HeFH})$ ), in addition to diet and maximum tolerated statin doses, in order to prevent CV events (122); alirocumab is instead indicated only for the treatment of HeFH (120).

In addition to the most characterizing feature of mAbs activity, i.e. LDL-cholesterol lowering (up to 50-60\%) in very high-risk patients $(123,124)$, especially FH (125), data from 35 RCTs $(45,539$ subjects) have shown that administration of these two mAbs is associated with a lower rate of MIs (Odds Ratio (OR): 0.72; 95\% Cl: 0.64-0.81), strokes (OR: 0.80; 95\% Cl: 0.67$0.96)$ and coronary revascularizations (OR: $0.78 ; 95 \% \mathrm{Cl}: 0.71-0.86)$ not of mortality (126). These findings have been confirmed in a subsequent meta-analysis from 11RCTs including 38,235 participants, treated with evolocumab and alirocumab for at least 48-weeks (127).

PCSK9 circulating levels have been related to a large number of CVD risk factors, i.e. LDLcholesterolemia (128), TGs (129), Lp(a) (130), atherogenic lipoproteins (131), arterial stiffness (132), and platelet activation (133). Moreover, a significant proportion of plasma PCSK9 (2040\%) circulates bound to lipoproteins, i.e. LDL and Lp(a) but not HDL (134).

The relationship between PCSK9 and the inflammatory process is the object of intensive investigation. While, in fact, inflammation raises PCSK9 liver expression (135) and PCSK9 is positively linked to TNF- $\alpha$ levels (136), no significant relationship has been observed between PCSK9 levels and hsCRP (137). This last finding is in line with the observation that PCSK9 antagonists do not apparently exert a significant anti-inflammatory activity in treated patients, at least as witnessed by a lack of reduction of hsCRP (weighed mean difference - WMD: 0.002 $\mathrm{mg} / \mathrm{L} ; 95 \% \mathrm{Cl}$ : $-0.017,0.021 ; \mathrm{p}=0.807)$. This conclusion is supported by the selective evaluation of alirocumab (WMD: $0.15 \mathrm{mg} / \mathrm{L}$ ) and evolocumab (WMD: $0.002 \mathrm{mg} / \mathrm{L}$ ) (138). Notably, data from the ODYSSEY COMBO II trial showed that alirocumab may work better in CV patients with residual lipid risk (LDL-C $>70 \mathrm{mg} / \mathrm{dL}$ ), vs those with residual inflammatory risk (CRP $>2 \mathrm{mg} / \mathrm{dL}$ ) (139). In this study, aimed at comparing the efficacy of alirocumab vs that of ezetimibe, this latter reduced, although not significantly, the hsCRP levels by $-25 \%$ vs no changes in patients given alirocumab (140). After 52 weeks of treatment, LDL-C dramatically dropped by $-49.5 \%$ in the alirocumab arm vs $-18.3 \%$ in ezetimibe patients (140) (Table 1). 
Interestingly, this lack of efficacy in reducing hsCRP persists independent of the mechanism by which PCSK9 is lowered; indeed, among patients at high risk of CV disease, allocated to receive a single dose of 200,300 , or $500 \mathrm{mg}$ of inclisiran or a two-dose regimen of 100,200 , or $300 \mathrm{mg}$ of inclisiran, only a modest $-16.7 \%(-50.9$ to $+33.3 ; p<0.05)$ decrement in hsCRP levels was found in the arm ( $=59)$ receiving inclisiran $300 \mathrm{mg}$ in the two dose regimen (141).

In a head-to-head analysis of mortality differences between the FOURIER (Further Cardiovascular Outcomes Research With PCSK9 Inhibition in Subjects With Elevated Risk) and the CANTOS trials, Ridker hypothesized that the lack of efficacy of evolocumab on cardiovascular or all-cause mortality may be due to the different baseline hsCRP levels, exceeding $4 \mathrm{mg} / \mathrm{L}$ in CANTOS, but less than $2 \mathrm{mg} / \mathrm{L}$ in FOURIER. Baseline LDL-C concentrations were instead similar in the two RCTs, i.e. $82 \mathrm{mg} / \mathrm{dL}$ in CANTOS vs $89 \mathrm{mg} / \mathrm{dL}$ in FOURIER (142). A post hoc analysis of the FOURIER trial reaffirms the importance of inflammatory and residual cholesterol risks, being LDL-C and hSCRP, in this trial, independently associated with the primary outcome. When patients were stratified according to baseline hsCRP, i.e. $<1,1-3$, and $>3 \mathrm{mg} / \mathrm{dL}$, absolute reductions were larger in patients with higher hsCRPs: $1.6 \%, 1.8 \%$, and $2.6 \%$ and $0.8 \%, 2.0 \%$, and $3.0 \%$, respectively, for the primary and key secondary endpoints across hsCRP strata (143). Moreover, even among patients achieving an LDL-C $<20 \mathrm{mg} / \mathrm{dL}$, the highest CV risk associated with the hsCRP stratum: a 3-year primary event rate of $9.0 \%, 10.8 \%$ and $13.1 \%$ occurred with hsCRPs of $<1,1$ to 3 or $>3 \mathrm{mg} / \mathrm{L}$, respectively (143) (Table 1 ).

These observations are in line with prior data analysis, reported by Catapano et al., observing how in RCTs with anti-PCSK9 therapies, median baseline hsCRPs were below $2 \mathrm{mg} / \mathrm{dL}$. Indeed, when clinical trials with hsCRP levels $>2 \mathrm{mg} / \mathrm{L}$ are considered, hsCRP are reduced by any lipid-lowering agent, independent of the mechanism of action (144).

Interestingly, the FOURIER trial highlighted how the severity and extent of coronary artery disease are leading features, in order to identify people who benefit the most from LDL-C lowering with evolocumab. Recent MI, multiple prior Mls, and residual multivessel coronary disease were independent predictors of CV outcomes, leading to an absolute risk reduction of over $3 \%$ in high risk vs. approximately $1 \%$ in low-risk groups, respectively. In patients with at least 1 high-risk feature there was a relative risk reduction in CV death, MI or stroke of 19\% (HR: $0.81 ; 95 \% \mathrm{Cl}: 0.68-0.95)$ during the first year and of $27 \%(\mathrm{HR}: 0.73 ; 95 \% \mathrm{Cl}: 0.62-0.86)$ beyond the first year (145). 
Another controversial point is whether the reduction of CV events in clinical trials with PCSK9 mAbs is related to a drop in LDL-C or in hSCRP: this will be better clarified once data from the ODISSEY OUTCOME (Evaluation of Cardiovascular Outcomes After an Acute Coronary Syndrome During Treatment With Alirocumab) trial will be fully available. Administration of alirocumab in patients with a recent acute coronary syndrome, already on intensive or maximum-tolerated statin therapy, reduced MACE (including all-cause mortality and MI) by $15 \%$, going down to $-24 \%$ in patients with baseline $L D L-C \geq 100 \mathrm{mg} / \mathrm{dL}$, deriving the largest benefit $(146,147)$. However, in the interpretation of these findings three important points should be borne in mind: among patients assigned to alirocumab (i) if at one month LDL-C remained at $\geq 50 \mathrm{mg} / \mathrm{dL}$ the dose of alirocumab was titrated in a blinded fashion to $150 \mathrm{mg}$ every 2 weeks; (ii) if on 2 consecutive evaluations LDL-C was $<25 \mathrm{mg} / \mathrm{dL}$, then the dose of alirocumab was reduced from 150 to $75 \mathrm{mg}$ and (iii) if LDL-C was $<15 \mathrm{mg} / \mathrm{dL}$ at 2 consecutive visits on alirocumab $75 \mathrm{mg}$, treatment was stopped (148).

The debate on whether or not LDL-C and hSCRP are inseparable markers of risk, was further addressed in a post hoc analysis of SPIRE-1 and -2 (Studies of PCSK9 Inhibition and the Reduction of Vascular Events) trials, with bococizumab. While this latter led to a dramatic reduction in LDL-C (-60.5\% at 14 weeks) a monotonic increase in the incidence of the primary endpoint (myocardial infarction, stroke, unstable angina requiring urgent coronary revascularization, and cardiovascular death) was noted. When patients were stratified according to on-treatment hsCRP levels, i.e. $<1$ (Reference value), 1-3, and $>3 \mathrm{mg} / \mathrm{L}$ the Hazard ratios were $1,1.16(95 \% \mathrm{Cl} 0.81-1.66)$ and $1.62(95 \% \mathrm{Cl} 1.14-2.30)(149)$ (Table 1).

An improvement in endothelial function after a 2-month therapy with evolocumab has been also described an effect proportional to the LDL-C reduction. Indeed, a $-59 \%$ drop in LDL-C levels corresponded to a rise in flow-mediated dilation (+40\%), brachial artery diameter (peak values $0.39 \pm 0.09$ vs $0.36 \pm 0.11 \mathrm{~cm}$ ) and velocity time integral (peak levels $96 \pm 1$ vs $85 \pm 9$ $\mathrm{cm}$ ). This evidence is in line with previous studies reporting a positive association between PCSK9 and endothelial function markers, e.g. blood pressure and arterial stiffness $(132,150-$ 152)

The anti-inflammatory activity of PCSK9 antagonists thus appears to be of a minimal extent (Figure 1); it has not been evaluated after the long-acting siRNA antagonist inclisiran (153). This does not exclude the possibility that individual hsCRP elevations may identify patients getting the largest benefit from PCSK9 antagonism. 
PCSK9 antagonists display also a clear lowering effect on Lp(a) levels, compared to the absence of effect by statins. The $L p(a)$ reductions was roughly $25 \%$ (154) by as yet unclear mechanisms. It appears the reductions are achieved through two different mechanisms. When administered as monotherapy, evolocumab reduces the production rate of $L p(a)$, not of fractional catabolic rate (FCR) (155). Differently when given in combination with atorvastatin the FCR of $L p(a)$ increases significantly, without alterations of the production rate. This most recent study differs somewhat from previous findings. A prior study, with alirocumab vs placebo a reduction of plasma $L p(a)$ levels $18.7 \%(p<0.001)$ was observed. This reduction appeared to be associated with a trend for an increase of median FCR of apo(a) $(+24.6 \%$, $p=0.09)$ with no change in the production rate (156).

The mechanism/s underlying these discordant findings may be possibly related to differences in Lp(a) baseline levels, age, body mass index and ethnicity. Apo(a) isoform size may play also a role, influencing both production and catabolism of $L p(a)$ particles (157). The $L p(a)$ lowering activity of PCSK9 antagoniss may be also related to the dramatic LDL-C reduction, thus reducing a possible competitor for the binding to the LDL-R, although targeted studies addressing this mechanism did not clearly indicate an involvement of the LDL-R in the uptake of $L p(a)$ (158). It may not be, of course, to be excluded that additional receptor/pathways may be involved in the clearance of $L p(a)$ (159).

Most recently, inclisiran has been evaluated in terms of $L p(a)$ reduction. In this study, patients on maximal tolerated drug therapy received single $(200,300$ and $500 \mathrm{mg})$ or two dose starting regimens $(100,200$ or $300 \mathrm{mg}$ on days 1 and 90) vs placebo. In addition to the expected reduction of $L D L-C$ and apo $B$ levels, changes of $L p(a)$ were indicative of a general trend to reduction, $80 \%$ of participants showing reduced $L p(a)$ levels at the end of the trial. However, due to the very large variability of levels, none of the difference reached statistical significance (153).

\subsection{Bile acid sequestrants}

Bile acid sequestrants (BAS) bind bile acids in the intestine through anion exchange, resulting in decreased enterohepatic recirculation of bile acids. This promotes liver conversion of cholesterol to bile acids. The reduction in the hepatocyte cholesterol content enhances LDL-R expression, that leads to lowering of LDL-C levels. Three BAS are currently available: cholestyramine, colestipol and colesevelam. Only two randomized controlled trials evaluated the effects of BAS on CHD risk. The Lipid Research Clinics Coronary Primary Prevention Trial 
evaluated use of cholestyramine $24 \mathrm{~g} /$ day versus placebo in patients with type II hyperlipoproteinemia free of CHD (160). Cholestyramine determined a significant $-8 \%$ LDL-C reduction, determining a $-19 \%$ lower risk of the primary end point (CHD death and nonfatal MI) after 7.4 years of follow-up (160). Colestipol ( $5 \mathrm{~g}$ three times daily vs placebo) has been investigated for efficacy, safety, and effects on mortality in CHD patients (161). Colestipol significantly reduced total cholesterol $(-32 \mathrm{mg} / \mathrm{dL})$ and raised TGs $(+33 \mathrm{mg} / \mathrm{dL})$ vs placebo and was associated with a significant reduction in CHD deaths in men, not in women (161).

Colesevelam hydrochloride is a newer BAS, specifically designed with a unique structure for the purpose of improving tolerability and reducing potential drug interactions compared to older BAS. Colesevelam $\mathrm{HCl}$ is hydrophilic, insoluble in water, and is administered orally as a solid tablet, containing $625 \mathrm{mg}$ of the product, not hydrolyzed by digestive enzymes and not undergoing intestinal absorption. It is excreted exclusively in the feces.

When given as monotherapy, six $625 \mathrm{mg}$ tablets colesevelam $\mathrm{HCl}$ per day, reduced LDL-C by $-15 \%$ to $21 \%$, increased HDL-C by $3 \%-9 \%$, and TG levels by $2 \%-16 \%$ compared to placebo (162). Compared to statin alone, colesevelam $\mathrm{HCl}$ in combination with statins, further decreased LDL-C by $-10 \%$ to $16 \%$, increased HDL-C by $3 \%-7 \%$, and TG levels by $5 \%-23 \%$ (162). Colesevelam $\mathrm{HCl}$ was the first BAS reported to reduce hsCRP when added to statins (163). The results derived from three clinical trials of similar design and methods, investigating the efficacy of adding colesevelam $\mathrm{HCl}$, compared with placebo, in hypercholesterolemic patients on stable simvastatin, atorvastatin, or pravastatin therapy (163). Pooled analysis of the three trials showed that the groups receiving the BAS plus statin had significantly larger mean reductions in LDL-C levels (-10.2\% vs $-21.0 \%)$ and produced a further significant reduction of hsCRP (-2.0 vs $1.3 \mathrm{mg} / \mathrm{L} ;-23.3 \%)$ (163) (Table 1).

Thus, the results from these trials showed that combining colesevelam $\mathrm{HCl}$ with either simvastatin, atorvastatin or pravastatin determines a significantly greater median percent reduction in hSCRP levels.

A third generation BAS, colestimide (also known as colestilan, marketed only in Japan) was also reported to reduce hsCRP levels (164). Japanese patients with diabetes mellitus complicated by hyperlipidemia and metabolic syndrome were enrolled and treated with pitavastatin or colestimide (164). Pitavastatin and colestimide reduced LDL-C by $-45.3 \%$ and $14.4 \%$, respectively. Pitavastatin only slightly reduced hsCRP after 24 weeks of treatment (from $8.76 \mathrm{mg} / \mathrm{L}$ to $8.27 \mathrm{mg} / \mathrm{L} ;-5.5 \%$ ) whereas colestimide exerted a much greater reduction (from $10.16 \mathrm{mg} / \mathrm{L}$ to $5.86 \mathrm{mg} / \mathrm{L} ;-42.3 \%)$ (164) (Table 1). 
BAS, while not extensively investigated (first generation cholestyramine and colestipol were developed way before the inflammatory mechanism of atherosclerosis was postulated) appear to produce a greater anti-inflammatory activity than expected (Figure 1). While colesevelam significantly adds to the hsCRP reducing activity by statins, the comparative evaluation of colestimide with pitavstatin suggested a dramatic hsCRP lowering potential.

\subsection{Lomitapide and Mipomersen}

Two drugs have been developed for the treatment of extreme cholesterol elevations, i.e. homozygous hypercholesterolemia. One of them, mipomersen is an apolipoprotein B synthesis inhibitor, acting as an antisense oligonucleotide, binding to the mRNA coding for apo B100. Mipomersen, mainly because of the high number of side effects, related to the s.c. administration, has not been approved for use outside of the US. Lomitapide is instead an agent affecting the microsomal triglyceride transfer protein (MTP). Inhibition of MTP prevents the assembly of apo B containing lipoproteins in enterocytes and liver cells. Lomitapide has been approved worldwide for the treatment of homozygous hypercholesterolemia.

\subsubsection{Lomitapide}

Lomitapide has an absolute bioavailability of approximately $7 \%$, suggesting a significant firstpass effect. The steady state volume of distribution is about $985-1292 \mathrm{~L}$, being $99.8 \%$ plasmaprotein bound. It is extensively metabolized by CYP3A4 and co-administration with strong CYP3A4 inhibitors, e.g. ketoconazole or, to a more modest extent, atorvastatin, increase the systemic exposure of lomitapide (165). The metabolites of lomitapide are essentially devoid of pharmacological activity. About $52.9-59.5 \%$ of the drug are eliminated by urinary and 33.4$35.1 \%$ by the fecal routes; the terminal half-life is $39.7 \mathrm{~h}(166,167)$.

Lomitapide administration is mainly associated with gastrointestinal disturbances, generally overcome after prolonged treatment (167). Clinical studies have generally not been addressed to the evaluation of inflammatory/anti-inflammatory markers, but of special interest is the very long study on efficacy/safety in homozygous hypercholesterolemic patients (168). Extensive evaluation of patients over 246 weeks of treatment noted, in addition to a very effective LDL-cholesterol reduction (-45.5\%) maintained for duration of the trial, a moderate rise in liver fat (from 0.7 to $10.2 \%$ ) and, most interestingly, a progressive reduction of hsCRP, resulting in a highly significant change, i.e. $-60 \%$ from baseline to week 24 (Table 1). 
This finding is difficult to explain but certainly of high clinical interest, since the occurrence of cardiovascular events has been minimal in patients treated for these very long periods. It differentiates lomitapide from PCSK9 antagonists, having no activity on CRP levels (138). It may be possibly linked to the drug's activity on the human ether-a-go-go-related gene (hERG) channel currents. Inhibition has been observed only at high concentration (>1.7 $\mu \mathrm{M})$ relative to those achieved at clinical dosing (166). However, a similar activity on hERG channels is exerted by COX2 antagonists, e.g. celecoxib (169) and is certainly linked to hsCRP reduction. The parallel activity of lomitapide and celecoxib on hERG channels and hsCRP may thus be explained by a common mechanism. Pharmacological connection of hERG channel inhibition and drug-induced prolongation of QT intervals has not come out of clinical studies on either celecoxib or lomitapide.

\subsubsection{Mipomersen}

Mipomersen is rapidly absorbed from the injection site into the circulation, with peak plasma concentrations within 3-4 h. No differences in AUCs have been reported between routes of administration (i.v. or s.c.). Relative to i.v. administration, the estimated absolute bioavailability ranges from $54 \%$ to $78 \%$. About $85 \%$ of mipomersen is bound to plasma proteins being albumin the prominent one. Tissue endonucleases cleave the molecule to chain-shortened metabolites that no longer retain pharmacological activity. Urinary excretion represents the main route of whole-body clearance for both parent drug and metabolites. Following s.c. administration, the elimination half-life is approximately 1 to 2 months $(170,171)$.

Mipomersen has been evaluated in a single study, to a limited extent, as potentially acting on inflammation. Flaim et al (172) tested the tolerability in healthy volunteers, determining plasma concentrations across three dose regimens. LDL-C reductions ranged between -9.5 and $-21 \%$. There were no significant changes in pro-inflammatory or antiinflammatory markers, except for a rise in post-dose hsCRP in the mipomersen $200 \mathrm{mg}$ weekly group. It appears thus as unlikely that mipomersen may display any significant antiinflammatory actions, also considering that the major side effects are the frequent occurrence of flu-like symptoms and injection site reactions (173).

In conclusion, lomitapide and mipomersen in clinical use for extreme lipid elevations appear to differ in terms of possible inflammatory/anti-inflammatory mechanisms. Mipomersen, an antisense DNA drug, leads to local inflammation and flu-like symptoms not associated with hsCRP reduction, but rather rises. Dramatic reductions of hsCRP have instead 
been observed after long term lomitapide and appear to be of potentially high clinical interest in the CV preventive activity.

\subsection{Bempedoic acid}

Bempedoic acid is a novel synthetic lipid-lowering agent targeting ATP-citrate lyase. ATP-citrate lyase $(A C L)$ is a seldom-evaluated enzyme target, uniquely positioned at the intersection of nutrient catabolism and fatty acid biosynthesis. The $A C L$ reaction is primarily responsible for the production of extra-mitochondrial acetyl-CoA (174), serving as the carbon precursor for cholesterol and fatty acid biosynthesis, as well as a metabolic checkpoint used by cells to sense nutrient availability and to coordinate metabolic adaptations. Bempedoic acid provides thus an effective therapeutic modality to treat hypercholesterolemia and to potentially address metabolically linked disorders such as non-alcoholic fatty liver disease. By a Mendelian randomization study the effects of lowering LDL-C levels were found to be mediated by multiple independent single nucleotide polymorphisms (SNPS) in the region encoding the ACLY gene (175).

The efficacy of bempedoic acid as an LDL-C lowering agent has been validated by the positive results of phase 3 studies, indicating a stable LDL-C reduction in the range of 25-35\%, additional to that of statins, with minimal muscular side effects (176). Bempedoic acid is, in fact, a pro-drug activated to the-CoA derivative in the liver by the very-long-chain acyl-CoA synthase 1 (ACSVL1). The active derivative inhibits $A C L$ in the liver, whereas no conversion occurs in skeletal muscle, lacking ACSVL 1 (177). Thus, different from statins, no significant amount of active drug reaches skeletal muscles, with consequent minimal risk of myalgia. Kinetic data on bempedoic have not, yet, been made available (Esperion Therapeutics, personal communication).

Clinical studies have consistently shown a marked hSCRP lowering activity of bempedoic acid. The highest efficacy has been reported in diabetic patients (178), i.e. $-41 \%$ with a similar LDL-C reduction on a daily dose of $120 \mathrm{mg}$. In hypercholesterolemic patients (LDL-C: 130-220 $\mathrm{mg} / \mathrm{dl}$, stratified by baseline TGs), hsCRP reductions of $20 \div 26 \%$ not dose-related, were described (179). More recently, in patients intolerant to at least one statin with a history of muscle complaints, a median $-42 \%$ hsCRP reduction was reported with daily doses up to 240 mg; bempedoic acid reduced LDL-C $28.7 \%$ more than placebo (180). In the CLEAR Tranquility trial, enrolling 269 statin intolerant patients, treatment with bempedoic acid (180 $\mathrm{mg}$ ) added to background lipid-modifying therapy that included ezetimibe reduced LDL-C and hSCRP by - 
$28.5 \%$ and $-31 \%$, respectively (181) (Table 1 ). The long-term safety and efficacy of bempedoic acid as well as the CV outcomes are being evaluated in other 3 ongoing clinical trials (182).

Finally, data from a phase $2 \mathrm{~b}$ study, showed that in hypercholesterolemic patients (LDLC, $130-220 \mathrm{mg} / \mathrm{dL}$ ) with or without muscle-related intolerance to $\geq 2$ statins, combination of bempedoic acid (120 or $180 \mathrm{mg}$ ) with ezetimibe (10 m/day) dramatically reduced LDL-C cholesterol up to $-48 \%$ with, in addition, a maximal $-40.2 \%$ reduction in hsCRP when bempedoic was administered as a monotherapy (183).

\subsection{Cholesteryl ester transfer protein inhibitors}

Cholesteryl ester transfer protein CETP is a hydrophobic glycoprotein promoting a net mass transfer of cholesteryl esters from the nonatherogenic HDL fraction to the potentially proatherogenic non-HDL, an event followed by a reciprocal transfer of TGs from LDL, VLDL to HDL (184). CETP inhibitors prevent neutral lipid transfers between HDLs and TG-rich lipoproteins, including VLDL, markedly raising HDL-C levels and, to a lesser extent, lowering LDL-C, depending on their potency (185). Overall, CETP inhibitors that have reached late stage clinical development are categorized into CETP inhibitors (torcetrapib, evacetrapib and anacetrapib) and modulators (dalcetrapib) (14). Despite the beneficial influence on cholesterol metabolism, off-target effects and lack of reduction in CV events and mortality (with torcetrapib, dalcetrapib and evacetrapib) have highlighted the complex, unclear beneficial mechanism of CETP inhibition (186).

In the ILLUMINATE (Investigation of Lipid Level Management to Understand its Impact in Atherosclerotic Events) trial, recruiting 15,067 patients at high CV risk, administration of torcetrapib (60 mg) on an atorvastatin background $(10,20,40$ and $80 \mathrm{mg})$, raised HDL-C by $+70.3 \%$ with a $-27.9 \%$ reduction in LDL-C; no changes in hsCRP were found $(+0.04 \mathrm{mg} / \mathrm{L})$. The trial was stopped after a 18-month follow-up after the observation of increased mortality and morbidity risk (187) (Table 1). A similar trend in lipoprotein changes was reported in the ACCELERATE (Assessment of Clinical Effects of Cholesteryl Ester Transfer Protein Inhibition with Evacetrapib in Patients at a High Risk for Vascular Outcomes) trial with evacetrapib. Among the 12,092 high-risk vascular patients, randomly assigned to receive evacetrapib (130 mg), HDL-C was impressively increased by $+131.6 \%$ with a $-37.1 \%$ drop in LDL-C. Levels of hsCRP were significantly higher $(+8.6 \%)$ in the evacetrapib vs the placebo group. The trial was stopped for futility after a median follow-up of 26 months (188) (Table 1). 
The only trial, i.e. the REVEAL (Randomized EValuation of the Effects of Anacetrapib Through Lipid-modification) study, demonstrating a significant 9\% proportional reduction of major coronary events upon anacetrapib administration (100 mg), reported no data on hsCRP. In this study, $a+104 \%$ rise of HDL-C and a $-41 \%$ reduction of LDL-C (as quantified by a direct method) were found (189). Interestingly, with a weaker CETP inhibitor, i.e. dalcetrapib in the dal-OUTCOMES trial - the HDL-C rise was $+30 \%$, with no change in LDL-C and a $+18 \%$ increment of hsCRP (190) (Table 1). Re-evaluation of all of these apparently negative results by using a pharmacogenomic approach has very recently unearthed unexpected findings. Among carriers of the AA genotype of the ADCY9 (adenylate cyclase type 9) gene, administration of dalcetrapib significantly reduced by $39 \%$ the risk of CV events with no elevation in hsCRP (191). This observation is now the object of the on-going dal-GenE trial (Effect of Dalcetrapib vs Placebo on CV Risk in a Genetically Defined Population With a Recent ACS; NCT02525939) (Table 1).

CETP antagonism does not appear to be related to clear-cut anti-inflammatory changes. Indeed, all studied antagonists had a tendency to induce hsCRP rises (Figure 1).

\subsection{Nicotinic acid}

Nicotinic acid (niacin or vitamin B3) is a natural compound exerting a variety of activities on lipids, both cholesterol and TGs, at pharmacological doses, i.e. about 1-2 g/day (192). Nicotinic acid (NA) exerts a powerful antilipolytic activity, resulting in reduced free fatty acid (FFA) release from the adipose tissue to the liver where FFAs may be resynthesized to TGs (193). Some Authors believe that NA may exert, similar to fibrates, an activity as a fraudulent fatty acid, i.e. exerting a moderate stimulation on peroxisomal proliferation as a PPAR $\alpha$ agonist (194). In this way NA may activate lipoprotein lipase and, as a consequence, reduce TGs, to a lesser extent LDL-C, and raise HDL-C levels (195). An analog of niacin, i.e. acipimox, has a more prolonged antilipolytic activity (196) and by this mechanism appears to be particularly effective in patients with the metabolic syndrome (197).

The profile of NA, particularly the significant positive impact on HDL-C levels, has led to large placebo controlled clinical studies in patients with atherosclerotic vascular disease, i.e. the Atherothrombotic Intervention in MetS with Low HDL/high triglycerides: Impact on Global Health Outcomes (AIM-HIGH) (198) and Heart Protection Study 2-Treatment of HDL to Reduce the Incidence of Vascular Events (HPS2-THRIVE) (199) both with extended release (ER) NA. These studies evaluated ER NA in combination with the anti-flushing agent laropiprant in patients on intensive statin therapy, plus ezetimibe when required to reach predetermined 
LDL-C target levels. Neither of these studies resulted in a significant reduction of major coronary disease. It is possible that this negative finding reflects the low baseline levels of LDL-C ( $\leq 75 \mathrm{mg} / \mathrm{dl}$ ) with associated modest reductions of LDL-C levels, although both studies reported a significant increase of HDL-C (200).

ER NA treatment is typically associated within the induction of insulin resistance (201). A likely mechanism is that the antilipolytic of NA is transient, followed by daily rises of FFA levels (195). The opposite case is that of acipimox, with a stable reduced lipolysis, also resulting in an improved lipid profile, increased affinity of LDL for their receptors (202) and reduced insulin resistance (197).

A very recent evaluation of ER NA given for 8 weeks in patients with dyslipidemia and metabolic syndrome (203), with $300 \mathrm{mg} /$ day aspirin to reduce flushing, reported increased insulin resistance: the HOMA index rose, in fact, from 5.80 to $7.67(+32 \%, p<0.015)$. This treatment also led to significant reductions of TG (-31\%) LDL-C (-17\%) and Lp(a) (-21\%) with concomitant reductions of apo B, apo CIII and apo $\mathrm{E}$. There were no changes in plasma apo Al but HDL-C levels rose by $+13.2 \%$.

Inflammatory markers are typically reduced by NA treatment. The cell-surface receptor GPR109A also known as hydroxycarboxylic acid receptor 2 (HCA2 or HCAR2) or niacin receptor 1 (NIACR1), is activated by NA. GPR109A is a G-protein-coupled receptor expressed in adipose tissue and immune cells (204). GPR109A KO mice show enhanced susceptibility to experimental inflammatory conditions (205). Extensive animal studies have confirmed the significant antiinflammatory potential of NA exerted via by the GPR109A receptor (206). In the above reported study in MetS patients (203), NA reduced hsCRP by $40 \%$ (from $2.7 \pm 0.55$ to $1.7 \pm 0.25$ $\mathrm{mg} / \mathrm{L}$ ) (Table 1), and similar, albeit lesser reductions, were noted for of TNF- $\alpha$, PAI1 (probably reflecting the reduction of TGs) and IL-7, not IL-6. It appears that the NA mediated reduction of CIII appeared to be tightly linked to an entire inflammatory cluster through hsCRP.

The findings of numerous studies of NA and analogs have not provided consistent results. In a comparative evaluation of NA and fenofibrate, the former was more effective at lowering hsCRP but fenofibrate led to more a beneficial lipoprotein profile (207). Acipimox may possibly have a different profile: this drug reduces neutrophil migration, with no effect on monocytes (197). 


\section{Conclusions}

Analysis of results from the more recent clinical trials conducted with the PCSK9 inhibitor evolocumab (FOURIER) and with the IL-1 $\beta$ antagonist canakinumab (CANTOS) confirmed the pioneer hypothesis by Ridker et al, i.e. that the largest CV event reduction can be obtained when treating patients with both $\mathrm{LDL}-\mathrm{C}>70 \mathrm{mg} / \mathrm{dl}$ and $\mathrm{hsCRP}>2 \mathrm{mg} / \mathrm{L}$ (3). Overall, the observation that canakinumab has no effects on diabetes and LDL cholesterolemia indicates that benefits on major CV events are due to inhibition of inflammation (57). However, it should be reminded that of the two other RCTs addressing the issue of inflammation and CV risk, CIRT (Cardiovascular Inflammation Reduction Trial) has been ended in May 2018 after recruiting 4,786 patients; the COLCOT (Colchicine Cardiovascular Outcomes Trial) is still ongoing. Results of CIRT are expected in November 2018. This study evaluated patients with prior MI and either type 2 diabetes or MetS, treated with low-dose methotrexate or placebo, primary endpoints being nonfatal MI, nonfatal stroke, and cardiovascular death (208). The COLCOT (Colchicine Cardiovascular Outcomes Trial) study instead aimed at evaluating whether long-term colchicine reduces rates of CV events in post-MI patients $(209,210)$.

The new biological agents thus contribute to dichotomizing the pharmacological action of statins, evolocumab lowering only the LDL-C levels and canakinumab reducing only systemic inflammation. The results of the two most recent trials (FOURIER and CANTOS) add, however, an extra-layer of complexity on the relationship between lipids, inflammation and CVD risk. Indeed, in the FOURIER trial, baseline hSCRP and achieved LDL-C were both factors independently associated with major adverse CV events, reaffirming the concept of raised inflammatory markers (in particular hsCRP) and residual CV risk (143).

Inflammation and cholesterolemia have thus different pathophysiological roles on atherosclerosis and CV risk (211). Lipid lowering agents with "pleiotropic" effects, i.e. statins, fibrates and, possibly, bempedoic acid, provide a potentially more effective approach to CV prevention. Looking back at 1997 when Maseri defined CRP as the "hidden side of the moon" (212), as a consequence of the never-ending debate relative to the direct causal role of inflammation in CVD, hsCRP appears to be of value in identifying high risk individuals, thus, guiding, in particular, lipid lowering therapy. Indeed, in the ASCOT (Anglo Scandinavian Cardiac Outcomes Trial) there was a $25 \%$ greater relative risk reduction among subjects with ontreatment hsCRP $<1.83 \mathrm{mg} / \mathrm{dL}$, a finding consistent across CARE, PROVE IT, REVERSAL, A to Z, and JUPITER trials (213). 
The most recent observations with the newer PCSK9 antagonist, alirocumab, require a more definite answer as to which patients will benefit the most from a profound LDL-C reduction. A recent meta-analysis evaluating threshold LDL-C levels for achieving CV risk reduction concluded, in fact, that patients with baseline $L D L-C \geq 100 \mathrm{mg} / \mathrm{dL}$ receiving a more intensive treatment are those benefitting the most (9). Evaluations of MACEs in the ODYSSEY trial did not show a clear benefit in patients with LDL-C $<100 \mathrm{mg} / \mathrm{dL}$. In the future, the effects of PCSK9 antagonism by RNA interference (inclisiran) will provide further, more stable cholesterol reductions and indications on their possible links with vascular inflammation. These pharmacological aspects of lipid lowering treatments will need to be more extensively addressed, both because of the present uncertainty on, e.g., statin treatment in elderlies (214) and because of the exposure of many patients to a growing number of drugs. 


\section{Tables and figures}

Figure 1. Pharmacological changes of LDL-C and CRP. Modified from Kinlay S et al. (6). CETP, Cholesteryl ester transfer protein; PCSK9, Proprotein convertase subtilisin/kexin 9;

Figure 2. Hazard ratios for major CV events, cardiovascular mortality and all-cause mortality were stratified according to on-treatment hsCRP concentrations at 3 months. 


\begin{tabular}{|c|c|c|c|c|c|c|c|}
\hline & Clinical study & \multicolumn{3}{|c|}{ hsCRP (mg/L) } & \multicolumn{3}{|c|}{ LDL-C (mg/dL) } \\
\hline & & Pre & post & $\Delta$ & pre & post & $\Delta$ \\
\hline $\begin{array}{c}\text { Monoclonal } \\
\text { antibody anti IL- } \\
1 \beta\end{array}$ & & & & & & & \\
\hline Canakinumab (52) & CANTOS & 4.3 & 2.0 & $-37 \%$ vs placebo & 82.4 & 84.7 & $\begin{array}{l}+3.1 \% \text { vs } \\
\text { placebo }\end{array}$ \\
\hline
\end{tabular}

\begin{tabular}{|c|c|c|c|c|c|c|c|}
\hline Statins & & & & & & & \\
\hline $\begin{array}{l}\text { Pravastatin (215, } \\
216)\end{array}$ & CARE & 2.3 & 1.9 & $\begin{array}{l}-17.4 \% \text { vs } \\
\text { baseline }\end{array}$ & 139.2 & 98.0 & $\begin{array}{l}-32 \% \text { vs } \\
\text { baseline }\end{array}$ \\
\hline Pravastatin (217) & PRINCE & 2.4 & 2.0 & $\begin{array}{l}-16.6 \% \text { vs } \\
\text { baseline }\end{array}$ & 142.9 & 97.5 & $\begin{array}{l}-31.8 \% \text { vs } \\
\text { baseline }\end{array}$ \\
\hline Lovastatin $(2,218)$ & AFCAPS/TexCAPS & 1.6 & 1.3 & $\begin{array}{l}-14.8 \% \text { vs } \\
\text { baseline }\end{array}$ & 156.0 & 115.0 & $\begin{array}{l}-27 \% \text { vs } \\
\text { baseline }\end{array}$ \\
\hline $\begin{array}{l}\text { Atorvastatin (219, } \\
220)\end{array}$ & MIRACL & 11.5 & 2.9 & $-75.0 \%$ vs placebo & 135.0 & & \% vs placebo \\
\hline Pravastatin (76) & REVERSAL & 3.0 & 2.9 & $-5.2 \%$ vs baseline & 150.2 & 110.4 & $\begin{array}{l}-25.2 \% \text { vs } \\
\text { baseline }\end{array}$ \\
\hline Atorvastatin (76) & REVERSAL & 3.0 & 1.8 & $\begin{array}{l}-36.4 \% \text { vs } \\
\text { baseline }\end{array}$ & 150.2 & 78.9 & $\begin{array}{l}-46.3 \% \text { vs } \\
\text { baseline }\end{array}$ \\
\hline $\begin{array}{l}\text { Pravastatin (73, } \\
221)\end{array}$ & $\begin{array}{c}\text { PROVE IT-TIMI } \\
22 \\
\end{array}$ & 11.9 & 2.1 & $\begin{array}{l}-82.4 \% \text { vs } \\
\text { baseline }\end{array}$ & 106.0 & 95.0 & $\begin{array}{l}-10.4 \% \text { vs } \\
\text { baseline }\end{array}$ \\
\hline $\begin{array}{l}\text { Atorvastatin (73, } \\
221)\end{array}$ & $\begin{array}{l}\text { PROVE IT-TIMI } \\
22\end{array}$ & 12.2 & 1.3 & $\begin{array}{l}-89.3 \% \text { vs } \\
\text { baseline }\end{array}$ & 106.0 & 62.0 & $\begin{array}{l}-41.5 \% \text { vs } \\
\text { baseline }\end{array}$ \\
\hline Simvastatin (222) & A-to-Z Trial & 2.01 & 0.17 & $\begin{array}{l}-91.5 \% \text { vs } \\
\text { baseline }\end{array}$ & 112.0 & 62.0 & $\begin{array}{l}-44.6 \% \text { vs } \\
\text { baseline }\end{array}$ \\
\hline Rosuvastatin (74) & JUPITER & 4.2 & & $\begin{array}{l}-47.6 \% \text { vs } \\
\text { baseline }\end{array}$ & 108.0 & 55.0 & $\begin{array}{l}-49.1 \% \text { vs } \\
\text { baseline }\end{array}$ \\
\hline Simvastatin (223) & $\begin{array}{c}\text { Heart Protection } \\
\text { Study }\end{array}$ & & & $-27 \%$ vs baseline & 127.9 & 95.9 & $\begin{array}{l}-25 \% \text { vs } \\
\text { baseline }\end{array}$ \\
\hline Atorvastatin (224) & ASCOT & & 1.8 & $\begin{array}{l}-25.8 \% \text { vs } \\
\text { baseline }\end{array}$ & 136.8 & 85.6 & $\begin{array}{l}-38.7 \% \text { vs } \\
\text { baseline }\end{array}$ \\
\hline Atorvastatin (225) & CARDS & 3 & 1.2 & $-9.8 \%$ vs baseline & 121.0 & 60.0 & $\begin{array}{l}-50.4 \% \text { vs } \\
\text { baseline }\end{array}$ \\
\hline
\end{tabular}

\begin{tabular}{|l|c|c|c|c|c|c|c|}
\hline \multicolumn{1}{|c|}{ Ezetimibe } & & & & & & & \\
\hline $\begin{array}{l}\text { Ezetimibe + } \\
\text { atorvastatin (226) }\end{array}$ & 2.19 & 1.98 & $\begin{array}{c}-10 \% \text { vs } \\
\text { atorvastatin }\end{array}$ & 101.8 & 89.5 & $\begin{array}{c}-12.1 \% \text { vs } \\
\text { atorvastatin }\end{array}$ \\
\hline $\begin{array}{l}\text { Ezetimibe + } \\
\text { rosuvastatin (227) }\end{array}$ & EXPLORER & 1.7 & 1.2 & $\begin{array}{c}-17.8 \% \text { vs } \\
\text { rosuvastatin }\end{array}$ & 81.5 & 56.9 & $\begin{array}{c}-30.2 \% \text { vs } \\
\text { rosuvastatin }\end{array}$ \\
\hline $\begin{array}{l}\text { Ezetimibe + } \\
\text { Simvastatin (88) }\end{array}$ & SHARP & 1.1 & 0.99 & $-21 \%$ vs placebo & 106.0 & 68.9 & $-35 \%$ vs placebo \\
\hline $\begin{array}{l}\text { Ezetimibe + } \\
\text { Simvastatin (87) }\end{array}$ & IMPROVE-IT & 1.9 & 1.6 & $\begin{array}{c}-14 \% \text { vs } \\
\text { simvastatin }\end{array}$ & 67.7 & 49.9 & $\begin{array}{c}-20 \% \text { vs } \\
\text { simvastatin }\end{array}$ \\
\hline
\end{tabular}

\begin{tabular}{|c|c|c|c|c|c|c|c|}
\hline Fibrates & & & & & & & \\
\hline Fenofibrate (105) & FIELD & 1.8 & 2.5 & $+38.9 \%$ vs & 120 & 103 & $-14.2 \%$ vs \\
\hline
\end{tabular}




\begin{tabular}{|l|c|c|c|c|c|c|c|}
\hline & & & & baseline & & & baseline \\
\hline $\begin{array}{l}\text { Fenofibrate }+ \\
\text { Simvastatin (108) }\end{array}$ & DIACOR & 2.2 & 2.1 & $\begin{array}{c}-15.9 \% \text { vs } \\
\text { baseline }\end{array}$ & 136.9 & 92.0 & $\begin{array}{c}-29.1 \% \text { vs } \\
\text { baseline }\end{array}$ \\
\hline $\begin{array}{l}\text { Fenofibrate }+ \\
\text { Ezetimibe (111) }\end{array}$ & 2.5 & 1.9 & $\begin{array}{c}-25.3 \% \text { vs } \\
\text { baseline }\end{array}$ & 159.7 & 124.6 & $\begin{array}{c}-22.0 \% \text { vs } \\
\text { baseline }\end{array}$ \\
\hline
\end{tabular}

\begin{tabular}{|l|c|c|c|c|c|c|c|}
\hline $\begin{array}{c}\text { Monoclonal } \\
\text { antibody anti } \\
\text { PCSK9 }\end{array}$ & \multicolumn{2}{|l|}{} & \multicolumn{2}{|l|}{} \\
\hline $\begin{array}{l}\text { Evolocumab (143, } \\
228)\end{array}$ & FOURIER & 1.7 & 1.4 & $0 \%$ vs placebo & 92.0 & 30.0 & $-59 \%$ vs placebo \\
\hline Bococizumab (149) & SPIRE-1 and -2 & 1.88 & 1.84 & $+6.6 \%$ vs placebo $\S$ & 96.5 & 34.7 & $\begin{array}{c}-60.5 \% \text { vs } \\
\text { placebo }\end{array}$ \\
\hline Alirocumab (140) & $\begin{array}{c}\text { ODYSSEY } \\
\text { COMBOII }\end{array}$ & 3.58 & 3.51 & $-2 \%$ vs baseline & 108.0 & 53.3 & $\begin{array}{c}-49.5 \% \text { vs } \\
\text { baseline }\end{array}$ \\
\hline
\end{tabular}

\begin{tabular}{|c|c|c|c|c|c|c|}
\hline $\begin{array}{c}\text { Bile acid } \\
\text { sequestrants }\end{array}$ & & & & & & \\
\hline $\begin{array}{l}\text { Colesevelam } \mathrm{HCl}+ \\
\text { statins (163) }\end{array}$ & 2.0 & 1.3 & $-23.3 \%$ vs statins & 132.6 & 111.3 & $-21 \%$ vs statins \\
\hline Colestimide (164) & 10.16 & 5.86 & $-42.3 \%$ & 151.2 & 127.3 & $\begin{array}{l}-14.4 \% \text { vs } \\
\text { baseline }\end{array}$ \\
\hline
\end{tabular}

\begin{tabular}{|c|c|c|c|c|c|c|c|}
\hline MTP inhibitor & & & & & & \\
\hline Lomitapide (168) & NCT00943306 & 2.0 & 1.1 & $\begin{array}{c}-45 \% \text { vs } \\
\text { baseline }\end{array}$ & 356.0 & 189.0 & $\begin{array}{c}-45.5 \% \text { vs } \\
\text { baseline }^{\#}\end{array}$ \\
\hline
\end{tabular}

\begin{tabular}{|l|l|l|l|l|l|l|l|}
\hline Bempedoic acid & & & & & & \\
\hline $\begin{array}{l}\text { Bempedoic acid + } \\
\text { ezetimibe (181) }\end{array}$ & CLEAR Tranquility & 2.2 & & $\begin{array}{l}-31 \% \text { vs } \\
\text { placebo }\end{array}$ & 129.8 & & $\begin{array}{c}-28.5 \% \text { vs } \\
\text { placebo }\end{array}$ \\
\hline
\end{tabular}

\begin{tabular}{|l|c|c|c|c|c|c|c|}
\hline \multicolumn{1}{|c|}{ CETP inhibitor } & \multicolumn{2}{|c|}{} & \multicolumn{3}{|c|}{} \\
\hline Torcetrapib (187) & ILLUMINATE & 1.30 & 1.34 & $+1 \%$ vs placebo & 79.7 & 60.5 & $-24 \%$ vs placebo \\
\hline \multirow{2}{*}{$\begin{array}{l}\text { Dalcetrapib (190, } \\
191)\end{array}$} & $\begin{array}{c}\text { dal-OUTCOMES } \\
\text { dal-OUTCOMES } \\
\text { (analyzed for } \\
\text { carriers of ADCY9 } \\
\text { AA genotype) }\end{array}$ & 1.5 & 1.6 & $+18 \%$ vs placebo & 76.4 & 76.4 & no changes \\
\hline Evacetrapib (188) & ACCELERATE & 1.52 & 1.65 & $+8.6 \%$ vs baseline & 81.6 & 54.7 & $\begin{array}{c}-37.1 \% \text { vs } \\
\text { placebo }\end{array}$ \\
\hline
\end{tabular}

\begin{tabular}{|c|c|c|c|c|c|c|c|}
\hline Nicotinic acid & & & & & & & \\
\hline Niacin (203) & NCT01216956 & 2.7 & 1.6 & $-40 \%$ vs baseline & 125 & 103 & $\begin{array}{c}-17 \% \text { vs } \\
\text { baseline }\end{array}$ \\
\hline
\end{tabular}

\#Data available at week $126 ;{ }^{\S}$ Data available at week 14 ; -, not available 
Declaration of interest: $\mathrm{MR}, \mathrm{NF}, \mathrm{CM}$ and $\mathrm{CS}$ have nothing to disclose; $\mathrm{AC}$ AC has received honoraria from AstraZeneca, AMGEN, Sanofi, Recordati, Novartis, MSD, Mediolanum, DOC, Mylan and Pfizer

\section{References}

1. Libby P. Inflammation in atherosclerosis. Arteriosclerosis, thrombosis, and vascular biology. 2012;32(9):2045-51.

2. Ridker PM, Rifai N, Clearfield M, Downs JR, Weis SE, Miles JS, et al. Measurement of Creactive protein for the targeting of statin therapy in the primary prevention of acute coronary events. The New England journal of medicine. 2001;344(26):1959-65.

3. Libby P, Ridker PM, Hansson GK, Leducq Transatlantic Network on A. Inflammation in atherosclerosis: from pathophysiology to practice. Journal of the American College of Cardiology. 2009;54(23):2129-38.

4. Ridker PM. Residual inflammatory risk: addressing the obverse side of the atherosclerosis prevention coin. European heart journal. 2016;37(22):1720-2.

5. Emerging Risk Factors C, Kaptoge S, Di Angelantonio E, Lowe G, Pepys MB, Thompson SG, et al. C-reactive protein concentration and risk of coronary heart disease, stroke, and mortality: an individual participant meta-analysis. Lancet. 2010;375(9709):132-40.

6. Kinlay S. Low-density lipoprotein-dependent and -independent effects of cholesterollowering therapies on C-reactive protein: a meta-analysis. Journal of the American College of Cardiology. 2007;49(20):2003-9.

7. Nordestgaard BG, Varbo A. Triglycerides and cardiovascular disease. Lancet. 2014;384(9943):626-35.

8. Silverman MG, Ference BA, Im K, Wiviott SD, Giugliano RP, Grundy SM, et al. Association Between Lowering LDL-C and Cardiovascular Risk Reduction Among Different Therapeutic Interventions: A Systematic Review and Meta-analysis. Jama. 2016;316(12):1289-97.

9. Navarese EP, Robinson JG, Kowalewski M, Kolodziejczak M, Andreotti F, Bliden K, et al. Association Between Baseline LDL-C Level and Total and Cardiovascular Mortality After LDL-C Lowering: A Systematic Review and Meta-analysis. Jama. 2018;319(15):1566-79.

10. Ference BA, Cannon CP, Landmesser U, Luscher TF, Catapano AL, Ray KK. Reduction of low density lipoprotein-cholesterol and cardiovascular events with proprotein convertase subtilisin-kexin type 9 (PCSK9) inhibitors and statins: an analysis of FOURIER, SPIRE, and the Cholesterol Treatment Trialists Collaboration. European Heart Journal. 2017.

11. Ray KK, Kastelein JJ, Boekholdt SM, Nicholls SJ, Khaw KT, Ballantyne CM, et al. The ACC/AHA 2013 guideline on the treatment of blood cholesterol to reduce atherosclerotic cardiovascular disease risk in adults: the good the bad and the uncertain: a comparison with ESC/EAS guidelines for the management of dyslipidaemias 2011. European heart journal. 2014;35(15):960-8.

12. Patel R, Janoudi A, Vedre A, Aziz K, Tamhane U, Rubinstein J, et al. Plaque rupture and thrombosis are reduced by lowering cholesterol levels and crystallization with ezetimibe and are correlated with fluorodeoxyglucose positron emission tomography. Arteriosclerosis, thrombosis, and vascular biology. 2011;31(9):2007-14.

13. Janoudi A, Shamoun FE, Kalavakunta JK, Abela GS. Cholesterol crystal induced arterial inflammation and destabilization of atherosclerotic plaque. European heart journal. 2016;37(25):1959-67.

14. Ferri N, Corsini A, Sirtori CR, Ruscica M. Present therapeutic role of cholesteryl ester transfer protein inhibitors. Pharmacological research. 2018;128:29-41. 
15. Crea F, Liuzzo G. Pathogenesis of acute coronary syndromes. Journal of the American College of Cardiology. 2013;61(1):1-11.

16. Duewell P, Kono H, Rayner KJ, Sirois CM, Vladimer G, Bauernfeind FG, et al. NLRP3 inflammasomes are required for atherogenesis and activated by cholesterol crystals. Nature. 2010;464(7293):1357-61.

17. Hansson GK. Inflammatory mechanisms in atherosclerosis. J Thromb Haemost. 2009;7 Suppl 1:328-31.

18. Libby $P$, Hansson GK. Taming Immune and Inflammatory Responses to Treat Atherosclerosis. Journal of the American College of Cardiology. 2018;71(2):173-6.

19. Fuster JJ, MacLauchlan S, Zuriaga MA, Polackal MN, Ostriker AC, Chakraborty R, et al. Clonal hematopoiesis associated with TET2 deficiency accelerates atherosclerosis development in mice. Science. 2017;355(6327):842-7.

20. Coll RC, Robertson AA, Chae JJ, Higgins SC, Munoz-Planillo R, Inserra MC, et al. A smallmolecule inhibitor of the NLRP3 inflammasome for the treatment of inflammatory diseases. Nat Med. 2015;21(3):248-55.

21. Wang YI, Schulze J, Raymond N, Tomita T, Tam K, Simon SI, et al. Endothelial inflammation correlates with subject triglycerides and waist size after a high-fat meal. Am J Physiol Heart Circ Physiol. 2011;300(3):H784-91.

22. Varbo A, Benn M, Tybjaerg-Hansen A, Nordestgaard BG. Elevated remnant cholesterol causes both low-grade inflammation and ischemic heart disease, whereas elevated low-density lipoprotein cholesterol causes ischemic heart disease without inflammation. Circulation. 2013;128(12):1298-309.

23. Chapman MJ, Ginsberg HN, Amarenco P, Andreotti F, Boren J, Catapano AL, et al. Triglyceride-rich lipoproteins and high-density lipoprotein cholesterol in patients at high risk of cardiovascular disease: evidence and guidance for management. European heart journal. 2011;32(11):1345-61.

24. Nordestgaard BG. Triglyceride-Rich Lipoproteins and Atherosclerotic Cardiovascular Disease: New Insights From Epidemiology, Genetics, and Biology. Circulation research. 2016;118(4):547-63.

25. Jun M, Foote C, Lv J, Neal B, Patel A, Nicholls SJ, et al. Effects of fibrates on cardiovascular outcomes: a systematic review and meta-analysis. Lancet. 2010;375(9729):187584.

26. Nordestgaard BG, Langsted A. Lipoprotein (a) as a cause of cardiovascular disease: insights from epidemiology, genetics, and biology. Journal of lipid research. 2016;57(11):195375.

27. Cao J, Steffen BT, Budoff M, Post WS, Thanassoulis G, Kestenbaum B, et al. Lipoprotein(a) Levels Are Associated With Subclinical Calcific Aortic Valve Disease in White and Black Individuals: The Multi-Ethnic Study of Atherosclerosis. Arteriosclerosis, thrombosis, and vascular biology. 2016;36(5):1003-9.

28. von Eckardstein A. Will you, nill you, I will treat you: the taming of lipoprotein(a). Eur Heart J. 2017;38(20):1570-2.

29. Nordestgaard BG, Chapman MJ, Ray K, Boren J, Andreotti F, Watts GF, et al. Lipoprotein(a) as a cardiovascular risk factor: current status. European heart journal. 2010;31(23):2844-53.

30. Lanktree MB, Rajakumar C, Brunt JH, Koschinsky ML, Connelly PW, Hegele RA. Determination of lipoprotein(a) kringle repeat number from genomic DNA: copy number variation genotyping using qPCR. Journal of lipid research. 2009;50(4):768-72. 
31. Mack S, Coassin S, Rueedi R, Yousri NA, Seppala I, Gieger C, et al. A genome-wide association meta-analysis on lipoprotein (a) concentrations adjusted for apolipoprotein (a) isoforms. Journal of lipid research. 2017;58(9):1834-44.

32. Feingold KR, Moser AH, Shigenaga JK, Patzek SM, Grunfeld C. Inflammation stimulates the expression of PCSK9. Biochem Biophys Res Commun. 2008;374(2):341-4.

33. Coassin S, Erhart G, Weissensteiner H, Eca Guimaraes de Araujo M, Lamina C, Schonherr $\mathrm{S}$, et al. A novel but frequent variant in LPA KIV-2 is associated with a pronounced $L p(a)$ and cardiovascular risk reduction. European heart journal. 2017;38(23):1823-31.

34. Nordestgaard BG, Langsted A. How Does Elevated Lipoprotein(a) Cause Aortic Valve Stenosis? Journal of the American College of Cardiology. 2015;66(11):1247-9.

35. Bergmark C, Dewan A, Orsoni A, Merki E, Miller ER, Shin MJ, et al. A novel function of lipoprotein [a] as a preferential carrier of oxidized phospholipids in human plasma. Journal of lipid research. 2008;49(10):2230-9.

36. Capoulade R, Chan KL, Yeang C, Mathieu P, Bosse Y, Dumesnil JG, et al. Oxidized Phospholipids, Lipoprotein(a), and Progression of Calcific Aortic Valve Stenosis. Journal of the American College of Cardiology. 2015;66(11):1236-46.

37. Calabresi L, Gomaraschi M, Franceschini G. Endothelial protection by high-density lipoproteins: from bench to bedside. Arteriosclerosis, thrombosis, and vascular biology. 2003;23(10):1724-31.

38. Gomaraschi M, Basilico N, Sisto F, Taramelli D, Eligini S, Colli S, et al. High-density lipoproteins attenuate interleukin-6 production in endothelial cells exposed to proinflammatory stimuli. Biochimica et biophysica acta. 2005;1736(2):136-43.

39. Theilmeier G, De Geest B, Van Veldhoven PP, Stengel D, Michiels C, Lox M, et al. HDLassociated PAF-AH reduces endothelial adhesiveness in apoE-/- mice. FASEB J. 2000;14(13):2032-9.

40. Favari E, Calabresi L, Adorni MP, Jessup W, Simonelli S, Franceschini G, et al. Small discoidal pre-beta1 HDL particles are efficient acceptors of cell cholesterol via ABCA1 and ABCG1. Biochemistry. 2009;48(46):11067-74.

41. Honda S, Sidharta SL, Shishikura D, Takata K, Di Giovanni GA, Nguyen T, et al. Highdensity lipoprotein cholesterol associated with change in coronary plaque lipid burden assessed by near infrared spectroscopy. Atherosclerosis. 2017;265:110-6.

42. Zewinger S, Kleber ME, Rohrer L, Lehmann M, Triem S, Jennings RT, et al. Symmetric dimethylarginine, high-density lipoproteins and cardiovascular disease. European heart journal. 2017;38(20):1597-607.

43. Elliott P, Chambers JC, Zhang W, Clarke R, Hopewell JC, Peden JF, et al. Genetic Loci associated with C-reactive protein levels and risk of coronary heart disease. Jama. 2009;302(1):37-48.

44. Collaboration CRPCHDG, Wensley F, Gao P, Burgess S, Kaptoge S, Di Angelantonio E, et al. Association between $C$ reactive protein and coronary heart disease: mendelian randomisation analysis based on individual participant data. BMJ. 2011;342:d548.

45. Lachmann HJ, Kone-Paut I, Kuemmerle-Deschner JB, Leslie KS, Hachulla E, Quartier P, et al. Use of canakinumab in the cryopyrin-associated periodic syndrome. The New England journal of medicine. 2009;360(23):2416-25.

46. Capodanno D, Angiolillo DJ. Canakinumab for secondary prevention of atherosclerotic disease. Expert Opin Biol Ther. 2018;18(2):215-20.

47. Chakraborty A, Tannenbaum S, Rordorf C, Lowe PJ, Floch D, Gram H, et al. Pharmacokinetic and pharmacodynamic properties of canakinumab, a human anti-interleukin1beta monoclonal antibody. Clin Pharmacokinet. 2012;51(6):e1-18.

48. Dhimolea E. Canakinumab. MAbs. 2010;2(1):3-13. 
49. Wang W, Wang EQ, Balthasar JP. Monoclonal antibody pharmacokinetics and pharmacodynamics. Clinical pharmacology and therapeutics. 2008;84(5):548-58.

50. Sun $H$, Van LM, Floch D, Jiang $X$, Klein UR, Abrams K, et al. Pharmacokinetics and Pharmacodynamics of Canakinumab in Patients With Systemic Juvenile Idiopathic Arthritis. J Clin Pharmacol. 2016;56(12):1516-27.

51. Libby P. Interleukin-1 Beta as a Target for Atherosclerosis Therapy: Biological Basis of CANTOS and Beyond. Journal of the American College of Cardiology. 2017;70(18):2278-89.

52. Ridker PM, Everett BM, Thuren T, MacFadyen JG, Chang WH, Ballantyne C, et al. Antiinflammatory Therapy with Canakinumab for Atherosclerotic Disease. The New England journal of medicine. 2017;377(12):1119-31.

53. Ibanez B, Fuster V. CANTOS: A Gigantic Proof-of-Concept Trial. Circulation research. 2017;121(12):1320-2.

54. Baylis RA, Gomez D, Mallat Z, Pasterkamp G, Owens GK. The CANTOS Trial: One Important Step for Clinical Cardiology but a Giant Leap for Vascular Biology. Arteriosclerosis, thrombosis, and vascular biology. 2017;37(11):e174-e7.

55. Harrington RA. Targeting Inflammation in Coronary Artery Disease. The New England journal of medicine. 2017;377(12):1197-8.

56. Ridker PM. Canakinumab for Residual Inflammatory Risk. European heart journal. 2017;38(48):3545-8.

57. Everett $B M$, Donath $M Y$, Pradhan $A D$, Thuren $T$, Pais $P$, Nicolau JC, et al. AntiInflammatory Therapy with Canakinumab for the Prevention and Management of Diabetes. Journal of the American College of Cardiology. 2018.

58. Lim GB. Diabetes: No benefit of canakinumab in diabetes prevention. Nat Rev Cardiol. 2018;15(5):256.

59. Ridker PM, MacFadyen JG, Everett BM, Libby P, Thuren T, Glynn RJ, et al. Relationship of C-reactive protein reduction to cardiovascular event reduction following treatment with canakinumab: a secondary analysis from the CANTOS randomised controlled trial. Lancet. 2018;391(10118):319-28.

60. Baigent C, Keech A, Kearney PM, Blackwell L, Buck G, Pollicino C, et al. Efficacy and safety of cholesterol-lowering treatment: prospective meta-analysis of data from 90,056 participants in 14 randomised trials of statins. Lancet. 2005;366(9493):1267-78.

61. Bellosta S, Paoletti R, Corsini A. Safety of statins: focus on clinical pharmacokinetics and drug interactions. Circulation. 2004;109(23 Suppl 1):III50-7.

62. Bellosta S, Ferri N, Bernini F, Paoletti R, Corsini A. Non-lipid-related effects of statins. Annals of medicine. 2000;32(3):164-76.

63. Ferri N, Paoletti R, Corsini A. Lipid-modified proteins as biomarkers for cardiovascular disease: a review. Biomarkers : biochemical indicators of exposure, response, and susceptibility to chemicals. 2005;10(4):219-37.

64. Diamantis E, Kyriakos G, Quiles-Sanchez LV, Farmaki P, Troupis T. The Anti-Inflammatory Effects of Statins on Coronary Artery Disease: An Updated Review of the Literature. Current cardiology reviews. 2017;13(3):209-16.

65. Corsini A, Ferri N, Cortellaro M. Are pleiotropic effects of statins real? Vasc Health Risk Manag. 2007;3(5):611-3.

66. Ferri N, Colombo G, Ferrandi C, Raines EW, Levkau B, Corsini A. Simvastatin reduces MMP1 expression in human smooth muscle cells cultured on polymerized collagen by inhibiting Rac1 activation. Arterioscler Thromb Vasc Biol. 2007;27(5):1043-9.

67. Khovidhunkit W, Kim MS, Memon RA, Shigenaga JK, Moser AH, Feingold KR, et al. Effects of infection and inflammation on lipid and lipoprotein metabolism: mechanisms and consequences to the host. Journal of lipid research. 2004;45(7):1169-96. 
68. Ruscica M, Baragetti A, Catapano AL, Norata GD. Translating the biology of adipokines in atherosclerosis and cardiovascular diseases: Gaps and open questions. Nutrition, metabolism, and cardiovascular diseases : NMCD. 2017;27(5):379-95.

69. Ridker PM, Rifai N, Pfeffer MA, Sacks FM, Moye LA, Goldman S, et al. Inflammation, pravastatin, and the risk of coronary events after myocardial infarction in patients with average cholesterol levels. Cholesterol and Recurrent Events (CARE) Investigators. Circulation. 1998;98(9):839-44.

70. Nissen SE, Tuzcu EM, Schoenhagen P, Crowe T, Sasiela WJ, Tsai J, et al. Statin therapy, LDL cholesterol, C-reactive protein, and coronary artery disease. N Engl J Med. 2005;352(1):2938.

71. Ridker PM, Morrow DA, Rose LM, Rifai N, Cannon CP, Braunwald E. Relative efficacy of atorvastatin $80 \mathrm{mg}$ and pravastatin $40 \mathrm{mg}$ in achieving the dual goals of low-density lipoprotein cholesterol $<70 \mathrm{mg} / \mathrm{dl}$ and C-reactive protein $<2 \mathrm{mg} / \mathrm{I}$ : an analysis of the PROVE-IT TIMI-22 trial. Journal of the American College of Cardiology. 2005;45(10):1644-8.

72. Morrow DA, de Lemos JA, Sabatine MS, Wiviott SD, Blazing MA, Shui A, et al. Clinical relevance of $C$-reactive protein during follow-up of patients with acute coronary syndromes in the Aggrastat-to-Zocor Trial. Circulation. 2006;114(4):281-8.

73. Ridker PM, Cannon CP, Morrow D, Rifai N, Rose LM, McCabe CH, et al. C-reactive protein levels and outcomes after statin therapy. N Engl J Med. 2005;352(1):20-8.

74. Ridker PM, Danielson E, Fonseca FA, Genest J, Gotto AM, Jr., Kastelein JJ, et al. Rosuvastatin to prevent vascular events in men and women with elevated C-reactive protein. The New England journal of medicine. 2008;359(21):2195-207.

75. Ridker PM, Danielson E, Fonseca FA, Genest J, Gotto AM, Jr., Kastelein JJ, et al. Reduction in C-reactive protein and LDL cholesterol and cardiovascular event rates after initiation of rosuvastatin: a prospective study of the JUPITER trial. Lancet. 2009;373(9670):1175-82.

76. Nissen SE, Tuzcu EM, Schoenhagen P, Brown BG, Ganz P, Vogel RA, et al. Effect of intensive compared with moderate lipid-lowering therapy on progression of coronary atherosclerosis: a randomized controlled trial. Jama. 2004;291(9):1071-80.

77. Fichtlscherer S, Schmidt-Lucke C, Bojunga S, Rossig L, Heeschen C, Dimmeler S, et al. Differential effects of short-term lipid lowering with ezetimibe and statins on endothelial function in patients with CAD: clinical evidence for 'pleiotropic' functions of statin therapy. Eur Heart J. 2006;27(10):1182-90.

78. Reriani MK, Dunlay SM, Gupta B, West CP, Rihal CS, Lerman LO, et al. Effects of statins on coronary and peripheral endothelial function in humans: a systematic review and metaanalysis of randomized controlled trials. European journal of cardiovascular prevention and rehabilitation : official journal of the European Society of Cardiology, Working Groups on Epidemiology \& Prevention and Cardiac Rehabilitation and Exercise Physiology. 2011;18(5):70416.

79. Sposito AC, Santos SN, de Faria EC, Abdalla DS, da Silva LP, Soares AA, et al. Timing and dose of statin therapy define its impact on inflammatory and endothelial responses during myocardial infarction. Arterioscler Thromb Vasc Biol. 2011;31(5):1240-6.

80. Zacho J, Tybjaerg-Hansen A, Jensen JS, Grande P, Sillesen H, Nordestgaard BG. Genetically elevated C-reactive protein and ischemic vascular disease. N Engl J Med. 2008;359(18):1897-908.

81. Subramanian S, Emami H, Vucic E, Singh P, Vijayakumar J, Fifer KM, et al. High-dose atorvastatin reduces periodontal inflammation: a novel pleiotropic effect of statins. Journal of the American College of Cardiology. 2013;62(25):2382-91. 
82. Altmann SW, Davis HR, Jr., Zhu L, Yao X, Hoos LM, Tetzloff G, et al. Niemann-Pick C1 Like 1 protein is critical for intestinal cholesterol absorption. Science. 2004;303(5661):1201-4.

83. Cannon CP, Blazing MA, Giugliano RP, McCagg A, White JA, Theroux $P$, et al. Ezetimibe Added to Statin Therapy after Acute Coronary Syndromes. N Engl J Med. 2015;372(25):2387-97.

84. Davidson $\mathrm{MH}$. Ezetimibe: a novel option for lowering cholesterol. Expert review of cardiovascular therapy. 2003;1(1):11-21.

85. Gomez-Garre D, Munoz-Pacheco P, Gonzalez-Rubio ML, Aragoncillo P, Granados R, Fernandez-Cruz A. Ezetimibe reduces plaque inflammation in a rabbit model of atherosclerosis and inhibits monocyte migration in addition to its lipid-lowering effect. British journal of pharmacology. 2009;156(8):1218-27.

86. Pearson TA, Ballantyne CM, Veltri E, Shah A, Bird S, Lin J, et al. Pooled analyses of effects on C-reactive protein and low density lipoprotein cholesterol in placebo-controlled trials of ezetimibe monotherapy or ezetimibe added to baseline statin therapy. Am J Cardiol. 2009;103(3):369-74.

87. Bohula EA, Giugliano RP, Cannon CP, Zhou J, Murphy SA, White JA, et al. Achievement of dual low-density lipoprotein cholesterol and high-sensitivity C-reactive protein targets more frequent with the addition of ezetimibe to simvastatin and associated with better outcomes in IMPROVE-IT. Circulation. 2015;132(13):1224-33.

88. Storey BC, Staplin N, Haynes R, Reith C, Emberson J, Herrington WG, et al. Lowering LDL cholesterol reduces cardiovascular risk independently of presence of inflammation. Kidney international. 2018;93(4):1000-7.

89. Araujo DB, Bertolami MC, Ferreira WP, Abdalla DS, Faludi AA, Nakamura $Y$, et al. Pleiotropic effects with equivalent low-density lipoprotein cholesterol reduction: comparative study between simvastatin and simvastatin/ezetimibe coadministration. J Cardiovasc Pharmacol. 2010;55(1):1-5.

90. Bulut D, Hanefeld C, Bulut-Streich N, Graf C, Mugge A, Spiecker M. Endothelial function in the forearm circulation of patients with the metabolic syndrome--effect of different lipidlowering regimens. Cardiology. 2005;104(4):176-80.

91. Kawagoe Y, Hattori Y, Nakano A, Aoki C, Tanaka S, Ohta S, et al. Comparative study between high-dose fluvastatin and low-dose fluvastatin and ezetimibe with regard to the effect on endothelial function in diabetic patients. Endocrine journal. 2011;58(3):171-5.

92. Landmesser U, Bahlmann F, Mueller M, Spiekermann S, Kirchhoff $N$, Schulz $S$, et al. Simvastatin versus ezetimibe: pleiotropic and lipid-lowering effects on endothelial function in humans. Circulation. 2005;111(18):2356-63.

93. Liu PY, Liu YW, Lin LJ, Chen JH, Liao JK. Evidence for statin pleiotropy in humans: differential effects of statins and ezetimibe on rho-associated coiled-coil containing protein kinase activity, endothelial function, and inflammation. Circulation. 2009;119(1):131-8.

94. Olijhoek JK, Hajer GR, van der Graaf Y, Dallinga-Thie GM, Visseren FL. The effects of lowdose simvastatin and ezetimibe compared to high-dose simvastatin alone on post-fat load endothelial function in patients with metabolic syndrome: a randomized double-blind crossover trial. J Cardiovasc Pharmacol. 2008;52(2):145-50.

95. Ostad MA, Eggeling S, Tschentscher P, Schwedhelm E, Boger R, Wenzel P, et al. Flowmediated dilation in patients with coronary artery disease is enhanced by high dose atorvastatin compared to combined low dose atorvastatin and ezetimibe: results of the CEZAR study. Atherosclerosis. 2009;205(1):227-32.

96. Settergren M, Bohm F, Ryden L, Pernow J. Cholesterol lowering is more important than pleiotropic effects of statins for endothelial function in patients with dysglycaemia and coronary artery disease. Eur Heart J. 2008;29(14):1753-60. 
97. Westerink J, Deanfield JE, Imholz BP, Spiering W, Basart DC, Coll B, et al. High-dose statin monotherapy versus low-dose statin/ezetimibe combination on fasting and postprandial lipids and endothelial function in obese patients with the metabolic syndrome: The PANACEA study. Atherosclerosis. 2013;227(1):118-24.

98. Grigore L, Raselli S, Garlaschelli K, Redaelli L, Norata GD, Pirillo A, et al. Effect of treatment with pravastatin or ezetimibe on endothelial function in patients with moderate hypercholesterolemia. European journal of clinical pharmacology. 2013;69(3):341-6.

99. Ferri N, Corsini A, Sirtori C, Ruscica M. PPAR-alpha agonists are still on the rise: an update on clinical and experimental findings. Expert Opin Investig Drugs. 2017;26(5):593-602.

100. Botta M, Audano M, Sahebkar A, Sirtori CR, Mitro N, Ruscica M. PPAR Agonists and Metabolic Syndrome: An Established Role? International journal of molecular sciences. 2018;19(4).

101. Elam MB, Ginsberg HN, Lovato LC, Corson M, Largay J, Leiter LA, et al. Association of Fenofibrate Therapy With Long-term Cardiovascular Risk in Statin-Treated Patients With Type 2 Diabetes. JAMA Cardiol. 2017;2(4):370-80.

102. Telford M. Clinical pharmacokinetics of fenofibrate. Curr Med Res Opin. 2003;19(2):139; author reply -40 .

103. Hao $Y$, Zhang $H$, Yang $X$, Wang L, Gu D. Effects of fibrates on C-reactive protein concentrations: a meta-analysis of randomized controlled trials. Clin Chem Lab Med. 2011;50(2):391-7.

104. Keech A, Simes RJ, Barter P, Best J, Scott R, Taskinen MR, et al. Effects of long-term fenofibrate therapy on cardiovascular events in 9795 people with type 2 diabetes mellitus (the FIELD study): randomised controlled trial. Lancet. 2005;366(9500):1849-61.

105. Hiukka A, Westerbacka J, Leinonen ES, Watanabe $H$, Wiklund $O$, Hulten LM, et al. Longterm effects of fenofibrate on carotid intima-media thickness and augmentation index in subjects with type 2 diabetes mellitus. J Am Coll Cardiol. 2008;52(25):2190-7.

106. Fievet C, Staels B. Combination therapy of statins and fibrates in the management of cardiovascular risk. Curr Opin Lipidol. 2009;20(6):505-11.

107. Corsini A, Bellosta S, Davidson MH. Pharmacokinetic interactions between statins and fibrates. The American journal of cardiology. 2005;96(9A):44K-9K; discussion 34K-5K.

108. Muhlestein JB, May HT, Jensen JR, Horne BD, Lanman RB, Lavasani F, et al. The reduction of inflammatory biomarkers by statin, fibrate, and combination therapy among diabetic patients with mixed dyslipidemiâ: the DIACOR (Diabetes and Combined Lipid Therapy Regimen) study. Journal of the American College of Cardiology. 2006;48(2):396-401.

109. Kei A, Liberopoulos E, Tellis K, Rizzo M, Elisaf M, Tselepis A. Effect of hypolipidemic treatment on emerging risk factors in mixed dyslipidemia: a randomized pilot trial. Eur J Clin Invest. 2013;43(7):698-707.

110. Agouridis AP, Tsimihodimos V, Filippatos TD, Dimitriou AA, Tellis CC, Elisaf MS, et al. The effects of rosuvastatin alone or in combination with fenofibrate or omega 3 fatty acids on inflammation and oxidative stress in patients with mixed dyslipidemia. Expert opinion on pharmacotherapy. 2011;12(17):2605-11.

111. McKenney JM, Farnier M, Lo KW, Bays HE, Perevozkaya I, Carlson G, et al. Safety and efficacy of long-term co-administration of fenofibrate and ezetimibe in patients with mixed hyperlipidemia. Journal of the American College of Cardiology. 2006;47(8):1584-7.

112. Ferri N, Corsini A, Macchi C, Magni P, Ruscica M. Proprotein convertase subtilisin kexin type 9 and high-density lipoprotein metabolism: experimental animal models and clinical evidence. Transl Res. 2016;173:19-29. 
113. Norata GD, Tavori H, Pirillo A, Fazio S, Catapano AL. Biology of proprotein convertase subtilisin kexin 9: beyond low-density lipoprotein cholesterol lowering. Cardiovasc Res. 2016;112(1):429-42.

114. Ferri N, Ruscica M. Proprotein convertase subtilisin/kexin type 9 (PCSK9) and metabolic syndrome: insights on insulin resistance, inflammation, and atherogenic dyslipidemia. Endocrine. 2016;54(3):588-601.

115. Ferri N, Corsini A, Sirtori CR, Ruscica M. Bococizumab for the treatment of hypercholesterolaemia. Expert Opin Biol Ther. 2017;17(2):237-43.

116. Ferri N, Corsini A, Sirtori CR, Ruscica M. Bococizumab for the treatment of hypercholesterolaemia. Expert Opin Biol Ther. 2017;17(7):909-10.

117. Nordestgaard BG, Nicholls SJ, Langsted A, Ray KK, Tybjaerg-Hansen A. Advances in lipidlowering therapy through gene-silencing technologies. Nat Rev Cardiol. 2018.

118. Landlinger C, Pouwer MG, Juno C, van der Hoorn JWA, Pieterman EJ, Jukema JW, et al. The AT04A vaccine against proprotein convertase subtilisin/kexin type 9 reduces total cholesterol, vascular inflammation, and atherosclerosis in APOE*3Leiden.CETP mice. European heart journal. 2017;38(32):2499-507.

119. Kasichayanula S, Grover A, Emery MG, Gibbs MA, Somaratne R, Wasserman SM, et al. Clinical Pharmacokinetics and Pharmacodynamics of Evolocumab, a PCSK9 Inhibitor. Clin Pharmacokinet. 2018.

120. U.S. S-A. Praluent (alirocumab injection) prescribing information. 2015

121. Ferri N, Bellosta S, Baldessin L, Boccia D, Racagni G, Corsini A. Pharmacokinetics interactions of monoclonal antibodies. Pharmacological research. 2016;111:592-9.

122. Evolocumab. REPATHA (evolocumab). 2017.

123. Qian L, Gao Y, Zhang YM, Chu M, Yao J, Xu D. Therapeutic efficacy and safety of PCSK9monoclonal antibodies on familial hypercholesterolemia and statin-intolerant patients: A metaanalysis of 15 randomized controlled trials. Sci Rep. 2017;7(1):238.

124. Masana L, Girona J, Ibarretxe D, Rodriguez-Calvo R, Rosales R, Vallve JC, et al. Clinical and pathophysiological evidence supporting the safety of extremely low LDL levels-The zeroLDL hypothesis. Journal of clinical lipidology. 2018.

125. Reiner Z. PCSK9 inhibitors in clinical practice: Expectations and reality. Atherosclerosis. 2018.

126. Karatasakis A, Danek BA, Karacsonyi J, Rangan BV, Roesle MK, Knickelbine T, et al. Effect of PCSK9 Inhibitors on Clinical Outcomes in Patients With Hypercholesterolemia: A MetaAnalysis of 35 Randomized Controlled Trials. J Am Heart Assoc. 2017;6(12).

127. Bai J, Gong LL, Li QF, Wang ZH. Long-term efficacy and safety of proprotein convertase subtilisin/kexin 9 monoclonal antibodies: A meta-analysis of 11 randomized controlled trials. Journal of clinical lipidology. 2018.

128. Welder G, Zineh I, Pacanowski MA, Troutt JS, Cao G, Konrad RJ. High-dose atorvastatin causes a rapid sustained increase in human serum PCSK9 and disrupts its correlation with LDL cholesterol. Journal of lipid research. 2010;51(9):2714-21.

129. Baragetti A, Grejtakova D, Casula M, Olmastroni E, Jotti GS, Norata GD, et al. Proprotein Convertase Subtilisin-Kexin type-9 (PCSK9) and triglyceride-rich lipoprotein metabolism: Facts and gaps. Pharmacological research. 2018;130:1-11.

130. Tavori H, Christian D, Minnier J, Plubell D, Shapiro MD, Yeang C, et al. PCSK9 Association With Lipoprotein(a). Circulation research. 2016;119(1):29-35.

131. Guardiola M, Plana N, Ibarretxe D, Cabre A, Gonzalez M, Ribalta J, et al. Circulating PCSK9 levels are positively correlated with NMR-assessed atherogenic dyslipidaemia in patients with high cardiovascular risk. Clin Sci (Lond). 2015;128(12):877-82. 
132. Ruscica M, Ferri N, Fogacci F, Rosticci M, Botta M, Marchiano S, et al. Circulating Levels of Proprotein Convertase Subtilisin/Kexin Type 9 and Arterial Stiffness in a Large Population Sample: Data From the Brisighella Heart Study. J Am Heart Assoc. 2017;6(5).

133. Camera M, Rossetti L, Barbieri SS, Zanotti I, Canciani B, Trabattoni D, et al. PCSK9 as a Positive Modulator of Platelet Activation. Journal of the American College of Cardiology. 2018;71(8):952-4.

134. Ruscica M, Simonelli S, Botta M, Ossoli A, Lupo MG, Magni P, et al. Plasma PCSK9 levels and lipoprotein distribution are preserved in carriers of genetic HDL disorders. Biochimica et biophysica acta. 2018;1863(9):991-7.

135. Ruscica M, Ferri N, Macchi C, Meroni M, Lanti C, Ricci C, et al. Liver fat accumulation is associated with circulating PCSK9. Ann Med. 2016;48(5):384-91.

136. Ricci C, Ruscica M, Camera M, Rossetti L, Macchi C, Colciago A, et al. PCSK9 induces a pro-inflammatory response in macrophages. Sci Rep. 2018;8(1):2267.

137. Ridker PM, Rifai N, Bradwin G, Rose L. Plasma proprotein convertase subtilisin/kexin type 9 levels and the risk of first cardiovascular events. European heart journal. 2016;37(6):55460.

138. Sahebkar A, Di Giosia P, Stamerra CA, Grassi D, Pedone C, Ferretti G, et al. Effect of monoclonal antibodies to PCSK9 on high-sensitivity C-reactive protein levels: a meta-analysis of 16 randomized controlled treatment arms. Br J Clin Pharmacol. 2016;81(6):1175-90.

139. Ruscica M, Ferri N, Corsini A, Sirtori CR. PCSK9 antagonists and inflammation. Atherosclerosis. 2018;268:235-6.

140. Cannon CP, Cariou B, Blom D, McKenney JM, Lorenzato C, Pordy R, et al. Efficacy and safety of alirocumab in high cardiovascular risk patients with inadequately controlled hypercholesterolaemia on maximally tolerated doses of statins: the ODYSSEY COMBO II randomized controlled trial. Eur Heart J. 2015;36(19):1186-94.

141. Ray KK, Landmesser U, Leiter LA, Kallend D, Dufour R, Karakas M, et al. Inclisiran in Patients at High Cardiovascular Risk with Elevated LDL Cholesterol. The New England journal of medicine. 2017;376(15):1430-40.

142. Ridker PM. Mortality Differences Associated with Treatment Responses in CANTOS and FOURIER: Insights and Implications. Circulation. 2017.

143. Bohula EA, Giugliano RP, Leiter LA, Verma S, Park JG, Sever PS, et al. Inflammatory and Cholesterol Risk in the FOURIER Trial (Further Cardiovascular Outcomes Research With PCSK9 Inhibition in Patients With Elevated Risk). Circulation. 2018.

144. Catapano AL, Pirillo A, Norata GD. Vascular inflammation and low-density lipoproteins: is cholesterol the link? A lesson from the clinical trials. Br J Pharmacol. 2017;174(22):3973-85.

145. Sabatine MS, De Ferrari GM, Giugliano RP, Huber K, Lewis BS, Ferreira J, et al. Clinical Benefit of Evolocumab by Severity and Extent of Coronary Artery Disease: An Analysis from FOURIER. Circulation. 2018.

146. Pocock SJ, Collier TJ. Critical Appraisal of the 2018 ACC Scientific Sessions Late-Breaking Trials From a Statistician's Perspective. Journal of the American College of Cardiology. 2018.

147. Steg P. The ODYSSEY Outcomes Trial: Topline Results. Paper presented at: American College of Cardiology Annual Scientific Session. 2018.

148. Schwartz GG, Bessac L, Berdan LG, Bhatt DL, Bittner V, Diaz R, et al. Effect of alirocumab, a monoclonal antibody to PCSK9, on long-term cardiovascular outcomes following acute coronary syndromes: rationale and design of the ODYSSEY outcomes trial. Am Heart J. 2014;168(5):682-9.

149. Pradhan AD, Aday AW, Rose LM, Ridker PM. Residual Inflammatory Risk On Treatment with PCSK9 Inhibition and Statin Therapy. Circulation. 2018. 
150. Yin RX, Wu JZ, Liu WY, Wu DF, Cao XL, Miao L, et al. Association of several lipid-related gene polymorphisms and blood pressure variation in the Bai $\mathrm{Ku}$ Yao population. Am J Hypertens. 2012;25(8):927-36.

151. Tran NT, Aslibekyan S, Tiwari HK, Zhi D, Sung YJ, Hunt SC, et al. PCSK9 variation and association with blood pressure in African Americans: preliminary findings from the HyperGEN and REGARDS studies. Front Genet. 2015;6:136.

152. Hachem A, Hariri E, Saoud P, Lteif C, Lteif L, Welty F. The Role of Proprotein Convertase Subtilisin/Kexin Type 9 (PCSK9) in Cardiovascular Homeostasis: A Non-Systematic Literature Review. Curr Cardiol Rev. 2017;13(4):274-82.

153. Ray KK, Stoekenbroek RM, Kallend D, Leiter LA, Landmesser U, Wright RS, et al. Effect of an siRNA Therapeutic Targeting PCSK9 on Atherogenic Lipoproteins: Pre-Specified Secondary End Points in ORION 1. Circulation. 2018.

154. Raal FJ, Giugliano RP, Sabatine MS, Koren MJ, Blom D, Seidah NG, et al. PCSK9 inhibitionmediated reduction in $\mathrm{Lp}(\mathrm{a})$ with evolocumab: an analysis of 10 clinical trials and the LDL receptor's role. Journal of lipid research. 2016;57(6):1086-96.

155. Watts GF, Chan DC, Somaratne R, Wasserman SM, Scott R, Marcovina SM, et al. Controlled study of the effect of proprotein convertase subtilisin-kexin type 9 inhibition with evolocumab on lipoprotein(a) particle kinetics. European heart journal. 2018.

156. Reyes-Soffer G, Pavlyha M, Ngai C, Thomas T, Holleran S, Ramakrishnan R, et al. Effects of PCSK9 Inhibition With Alirocumab on Lipoprotein Metabolism in Healthy Humans. Circulation. 2017;135(4):352-62.

157. Saleheen D, Haycock PC, Zhao W, Rasheed A, Taleb A, Imran A, et al. Apolipoprotein(a) isoform size, lipoprotein(a) concentration, and coronary artery disease: a mendelian randomisation analysis. The lancet Diabetes \& endocrinology. 2017;5(7):524-33.

158. Villard EF, Thedrez A, Blankenstein J, Croyal M, Tran TT, Poirier B, et al. PCSK9 Modulates the Secretion But Not the Cellular Uptake of Lipoprotein(a) Ex Vivo: An Effect Blunted by Alirocumab. JACC Basic to translational science. 2016;1(6):419-27.

159. Pirillo A, Catapano AL. PCSK9 inhibition and Lp(a) reduction: another piece of the puzzle? European heart journal. 2018.

160. The Lipid Research Clinics Coronary Primary Prevention Trial results. II. The relationship of reduction in incidence of coronary heart disease to cholesterol lowering. Jama. 1984;251(3):365-74.

161. Dorr AE, Gundersen K, Schneider JC, Jr., Spencer TW, Martin WB. Colestipol hydrochloride in hypercholesterolemic patients--effect on serum cholesterol and mortality. Journal of chronic diseases. 1978;31(1):5-14.

162. Bays $\mathrm{H}$, Dujovne $\mathrm{C}$. Colesevelam HCl: a non-systemic lipid-altering drug. Expert opinion on pharmacotherapy. 2003;4(5):779-90.

163. Bays HE, Davidson M, Jones MR, Abby SL. Effects of colesevelam hydrochloride on lowdensity lipoprotein cholesterol and high-sensitivity C-reactive protein when added to statins in patients with hypercholesterolemia. The American journal of cardiology. 2006;97(8):1198-205.

164. Kato T, Inagaki K, Sawai Y, Kanayama H, Katada N, Itoh M. Comparison of efficacy of pitavastatin and colestimide in Japanese patients with diabetes mellitus complicated by hyperlipidemia and metabolic syndrome. Experimental and clinical endocrinology \& diabetes : official journal, German Society of Endocrinology [and] German Diabetes Association. 2011;119(9):554-8.

165. Sirtori CR, Pavanello C, Bertolini S. Microsomal transfer protein (MTP) inhibition-a novel approach to the treatment of homozygous hypercholesterolemia. Ann Med. 2014;46(7):464-74.

166. information LD. JUXTAPID ${ }^{\circledR}$ (lomitapide) capsules, for oral use. 2016. 
167. Berberich AJ, Hegele RA. Lomitapide for the treatment of hypercholesterolemia. Expert opinion on pharmacotherapy. 2017;18(12):1261-8.

168. Blom DJ, Averna MR, Meagher EA, du Toit Theron H, Sirtori CR, Hegele RA, et al. LongTerm Efficacy and Safety of the Microsomal Triglyceride Transfer Protein Inhibitor Lomitapide in Patients With Homozygous Familial Hypercholesterolemia. Circulation. 2017;136(3):332-5.

169. Frolov RV, Ignatova, II, Singh S. Inhibition of HERG potassium channels by celecoxib and its mechanism. PLoS One. 2011;6(10):e26344.

170. Geary RS, Baker BF, Crooke ST. Clinical and preclinical pharmacokinetics and pharmacodynamics of mipomersen (kynamro((R))): a second-generation antisense oligonucleotide inhibitor of apolipoprotein B. Clin Pharmacokinet. 2015;54(2):133-46.

171. Injection KmsISfS. HIGHLIGHTS OF PRESCRIBING INFORMATION. 2016.

172. Flaim JD, Grundy JS, Baker BF, McGowan MP, Kastelein JJ. Changes in mipomersen dosing regimen provide similar exposure with improved tolerability in randomized placebocontrolled study of healthy volunteers. J Am Heart Assoc. 2014;3(2):e000560.

173. Duell PB, Santos RD, Kirwan BA, Witztum JL, Tsimikas S, Kastelein JJP. Long-term mipomersen treatment is associated with a reduction in cardiovascular events in patients with familial hypercholesterolemia. Journal of clinical lipidology. 2016;10(4):1011-21.

174. Pinkosky SL, Groot PHE, Lalwani ND, Steinberg GR. Targeting ATP-Citrate Lyase in Hyperlipidemia and Metabolic Disorders. Trends Mol Med. 2017;23(11):1047-63.

175. Ference $B$, Neff $D$, Cabot $M$, Catapano AL, Ray K. GENETIC TARGET VALIDATION FOR ATP-CITRATE LYASE INHIBITION. Journal of the American College of Cardiology. 2017;69(11):1655.

176. Burke AC, Huff MW. ATP-citrate lyase: genetics, molecular biology and therapeutic target for dyslipidemia. Curr Opin Lipidol. 2017;28(2):193-200.

177. Pinkosky SL, Newton RS, Day EA, Ford RJ, Lhotak S, Austin RC, et al. Liver-specific ATPcitrate lyase inhibition by bempedoic acid decreases LDL-C and attenuates atherosclerosis. Nat Commun. 2016;7:13457.

178. Gutierrez MJ, Rosenberg NL, Macdougall DE, Hanselman JC, Margulies JR, Strange P, et al. Efficacy and safety of ETC-1002, a novel investigational low-density lipoprotein-cholesterollowering therapy for the treatment of patients with hypercholesterolemia and type 2 diabetes mellitus. Arteriosclerosis, thrombosis, and vascular biology. 2014;34(3):676-83.

179. Ballantyne CM, Davidson MH, Macdougall DE, Bays HE, Dicarlo LA, Rosenberg NL, et al. Efficacy and safety of a novel dual modulator of adenosine triphosphate-citrate lyase and adenosine monophosphate-activated protein kinase in patients with hypercholesterolemia: results of a multicenter, randomized, double-blind, placebo-controlled, parallel-group trial. Journal of the American College of Cardiology. 2013;62(13):1154-62.

180. Thompson PD, Rubino J, Janik MJ, MacDougall DE, McBride SJ, Margulies JR, et al. Use of ETC-1002 to treat hypercholesterolemia in patients with statin intolerance. Journal of clinical lipidology. 2015;9(3):295-304.

181. Ballantyne CM, Banach M, Mancini GBJ, Lepor NE, Hanselman JC, Zhao X, et al. Efficacy and safety of bempedoic acid added to ezetimibe in statin-intolerant patients with hypercholesterolemia: A randomized, placebo-controlled study. Atherosclerosis. 2018;Available online 12 June 2018.

182. Saeed A, Ballantyne CM. Bempedoic Acid (ETC-1002): A Current Review. Cardiology clinics. 2018;36(2):257-64.

183. Thompson PD, MacDougall DE, Newton RS, Margulies JR, Hanselman JC, Orloff DG, et al. Treatment with ETC-1002 alone and in combination with ezetimibe lowers LDL cholesterol in hypercholesterolemic patients with or without statin intolerance. Journal of clinical lipidology. 2016;10(3):556-67. 
184. Barter PJ, Rye KA. Cholesteryl Ester Transfer Protein Inhibitors as Agents to Reduce Coronary Heart Disease Risk. Cardiology clinics. 2018;36(2):299-310.

185. Tall AR, Rader DJ. Trials and Tribulations of CETP Inhibitors. Circulation research. 2018;122(1):106-12.

186. Shrestha S, Wu BJ, Guiney L, Barter PJ, Rye KA. Cholesteryl ester transfer protein and its inhibitors. Journal of lipid research. 2018;59(5):772-83.

187. Barter P, Gotto AM, LaRosa JC, Maroni J, Szarek M, Grundy SM, et al. HDL cholesterol, very low levels of LDL cholesterol, and cardiovascular events. The New England journal of medicine. 2007;357(13):1301-10.

188. Lincoff AM, Nicholls SJ, Riesmeyer JS, Barter PJ, Brewer HB, Fox KAA, et al. Evacetrapib and Cardiovascular Outcomes in High-Risk Vascular Disease. The New England journal of medicine. 2017;376(20):1933-42.

189. Group HTRC, Bowman L, Hopewell JC, Chen F, Wallendszus K, Stevens W, et al. Effects of Anacetrapib in Patients with Atherosclerotic Vascular Disease. The New England journal of medicine. 2017;377(13):1217-27.

190. Schwartz GG, Olsson AG, Abt M, Ballantyne CM, Barter PJ, Brumm J, et al. Effects of dalcetrapib in patients with a recent acute coronary syndrome. The New England journal of medicine. 2012;367(22):2089-99.

191. Tardif JC, Rhainds D, Brodeur M, Feroz Zada Y, Fouodjio R, Provost S, et al. GenotypeDependent Effects of Dalcetrapib on Cholesterol Efflux and Inflammation: Concordance With Clinical Outcomes. Circulation Cardiovascular genetics. 2016;9(4):340-8.

192. Digby JE, Ruparelia N, Choudhury RP. Niacin in cardiovascular disease: recent preclinical and clinical developments. Arteriosclerosis, thrombosis, and vascular biology. 2012;32(3):582-8. 193. Wang W, Basinger A, Neese RA, Shane B, Myong SA, Christiansen M, et al. Effect of nicotinic acid administration on hepatic very low density lipoprotein-triglyceride production. American journal of physiology Endocrinology and metabolism. 2001;280(3):E540-7.

194. Watt MJ, Southgate RJ, Holmes AG, Febbraio MA. Suppression of plasma free fatty acids upregulates peroxisome proliferator-activated receptor (PPAR) alpha and delta and PPAR coactivator 1alpha in human skeletal muscle, but not lipid regulatory genes. Journal of molecular endocrinology. 2004;33(2):533-44.

195. Vega GL, Cater NB, Meguro S, Grundy SM. Influence of extended-release nicotinic acid on nonesterified fatty acid flux in the metabolic syndrome with atherogenic dyslipidemia. The American journal of cardiology. 2005;95(11):1309-13.

196. Fuccella LM, Goldaniga G, Lovisolo P, Maggi E, Musatti L, Mandelli V, et al. Inhibition of lipolysis by nicotinic acid and by acipimox. Clinical pharmacology and therapeutics. 1980;28(6):790-5.

197. Montecucco F, Bertolotto M, Vuilleumier N, Franciosi U, Puddu A, Minetti S, et al. Acipimox reduces circulating levels of insulin and associated neutrophilic inflammation in metabolic syndrome, American journal of physiology Endocrinology and metabolism. 2011;300(4):E681-90.

198. Investigators A-H, Boden WE, Probstfield JL, Anderson T, Chaitman BR, DesvignesNickens $P$, et al. Niacin in patients with low HDL cholesterol levels receiving intensive statin therapy. N Engl J Med. 2011;365(24):2255-67.

199. Group HTC, Landray MJ, Haynes R, Hopewell JC, Parish S, Aung T, et al. Effects of extended-release niacin with laropiprant in high-risk patients. The New England journal of medicine. 2014;371(3):203-12.

200. Superko HR, Zhao XQ, Hodis HN, Guyton JR. Niacin and heart disease prevention: Engraving its tombstone is a mistake. Journal of clinical lipidology. 2017;11(6):1309-17. 
201. Rotter V, Nagaev I, Smith U. Interleukin-6 (IL-6) induces insulin resistance in 3T3-L1 adipocytes and is, like IL-8 and tumor necrosis factor-alpha, overexpressed in human fat cells from insulin-resistant subjects. The Journal of biological chemistry. 2003;278(46):45777-84.

202. Franceschini G, Bernini F, Michelagnoli S, Bellosta S, Vaccarino V, Fumagalli R, et al. Lipoprotein changes and increased affinity of LDL for their receptors after acipimox treatment in hypertriglyceridemia. Atherosclerosis. 1990;81(1):41-9.

203. Adiels M, Chapman MJ, Robillard P, Krempf M, Laville M, Boren J, et al. Niacin action in the atherogenic mixed dyslipidemia of metabolic syndrome: Insights from metabolic biomarker profiling and network analysis. Journal of clinical lipidology. 2018.

204. Feingold KR, Moser A, Shigenaga JK, Grunfeld C. Inflammation stimulates niacin receptor (GPR109A/HCA2) expression in adipose tissue and macrophages. Journal of lipid research. 2014;55(12):2501-8.

205. Singh N, Gurav A, Sivaprakasam S, Brady E, Padia R, Shi H, et al. Activation of Gpr109a, receptor for niacin and the commensal metabolite butyrate, suppresses colonic inflammation and carcinogenesis. Immunity. 2014;40(1):128-39.

206. Wu BJ, Yan L, Charlton F, Witting P, Barter PJ, Rye KA. Evidence that niacin inhibits acute vascular inflammation and improves endothelial dysfunction independent of changes in plasma lipids. Arteriosclerosis, thrombosis, and vascular biology. 2010;30(5):968-75.

207. Wi J, Kim JY, Park S, Kang SM, Jang Y, Chung N, et al. Optimal pharmacologic approach to patients with hypertriglyceridemia and low high-density lipoprotein-cholesterol: randomized comparison of fenofibrate $160 \mathrm{mg}$ and niacin $1500 \mathrm{mg}$. Atherosclerosis. 2010;213(1):235-40.

208. Everett BM, Pradhan AD, Solomon DH, Paynter N, Macfadyen J, Zaharris E, et al. Rationale and design of the Cardiovascular Inflammation Reduction Trial: a test of the inflammatory hypothesis of atherothrombosis. Am Heart J. 2013;166(2):199-207 e15.

209. (NCT02551094) CCOT.

210. Martinez GJ, Celermajer DS, Patel S. The NLRP3 inflammasome and the emerging role of colchicine to inhibit atherosclerosis-associated inflammation. Atherosclerosis. 2018;269:26271.

211. Reklou A, Doumas M, Imprialos K, Stavropoulos K, Patoulias D, Athyros VG. Reduction of Vascular Inflammation, LDL-C, or Both for the Protection from Cardiovascular Events? The open cardiovascular medicine journal. 2018;12:29-40.

212. Maseri A. Inflammation, atherosclerosis, and ischemic events -- exploring the hidden side of the moon. The New England journal of medicine. 1997;336(14):1014-6.

213. Braunwald E. Creating controversy where none exists: the important role of $C$-reactive protein in the CARE, AFCAPS/TexCAPS, PROVE IT, REVERSAL, A to $Z$, JUPITER, HEART PROTECTION, and ASCOT trials. European heart journal. 2012;33(4):430-2.

214. Ruscica M, Macchi C, Pavanello C, Corsini A, Sahebkar A, Sirtori CR. Appropriateness of statin prescription in the elderly. Eur J Intern Med. 2018.

215. Sacks FM, Pfeffer MA, Moye LA, Rouleau JL, Rutherford JD, Cole TG, et al. The effect of pravastatin on coronary events after myocardial infarction in patients with average cholesterol levels. Cholesterol and Recurrent Events Trial investigators. N Engl J Med. 1996;335(14):1001-9. 216. Ridker PM, Rifai N, Pfeffer MA, Sacks F, Braunwald E. Long-term effects of pravastatin on plasma concentration of C-reactive protein. The Cholesterol and Recurrent Events (CARE) Investigators. Circulation. 1999;100(3):230-5.

217. Albert MA, Danielson E, Rifai N, Ridker PM, Investigators P. Effect of statin therapy on Creactive protein levels: the pravastatin inflammation/CRP evaluation (PRINCE): a randomized trial and cohort study. JAMA. 2001;286(1):64-70.

218. Downs JR, Clearfield M, Weis S, Whitney E, Shapiro DR, Beere PA, et al. Primary prevention of acute coronary events with lovastatin in men and women with average 
cholesterol levels: results of AFCAPS/TexCAPS. Air Force/Texas Coronary Atherosclerosis Prevention Study. JAMA. 1998;279(20):1615-22.

219. Kinlay S, Schwartz GG, Olsson AG, Rifai N, Leslie SJ, Sasiela WJ, et al. High-dose atorvastatin enhances the decline in inflammatory markers in patients with acute coronary syndromes in the MIRACL study. Circulation. 2003;108(13):1560-6.

220. Schwartz GG, Olsson AG, Ezekowitz MD, Ganz P, Oliver MF, Waters D, et al. Effects of atorvastatin on early recurrent ischemic events in acute coronary syndromes: the MIRACL study: a randomized controlled trial. JAMA. 2001;285(13):1711-8.

221. Cannon CP, Braunwald E, McCabe CH, Rader DJ, Rouleau JL, Belder R, et al. Intensive versus moderate lipid lowering with statins after acute coronary syndromes. $\mathrm{N}$ Engl J Med. 2004;350(15):1495-504.

222. de Lemos JA, Blazing MA, Wiviott SD, Lewis EF, Fox KA, White HD, et al. Early intensive vs a delayed conservative simvastatin strategy in patients with acute coronary syndromes: phase $Z$ of the A to $Z$ trial. JAMA. 2004;292(11):1307-16.

223. Heart Protection Study Collaborative G, Jonathan E, Derrick B, Emma L, Sarah P, John D, et al. C-reactive protein concentration and the vascular benefits of statin therapy: an analysis of 20,536 patients in the Heart Protection Study. Lancet. 2011;377(9764):469-76.

224. Sever PS, Poulter NR, Chang CL, Thom SA, Hughes AD, Welsh P, et al. Evaluation of Creactive protein before and on-treatment as a predictor of benefit of atorvastatin: a cohort analysis from the Anglo-Scandinavian Cardiac Outcomes Trial lipid-lowering arm. J Am Coll Cardiol. 2013;62(8):717-29.

225. Soedamah-Muthu SS, Livingstone SJ, Charlton-Menys V, Betteridge DJ, Hitman GA, Neil $H A$, et al. Effect of atorvastatin on C-reactive protein and benefits for cardiovascular disease in patients with type 2 diabetes: analyses from the Collaborative Atorvastatin Diabetes Trial. Diabetologia. 2015;58(7):1494-502.

226. Ballantyne CM, Houri J, Notarbartolo A, Melani L, Lipka $L$, Suresh R, et al. Effect of ezetimibe coadministered with atorvastatin in 628 patients with primary hypercholesterolemia: a prospective, randomized, double-blind trial. Circulation. 2003;107(19):2409-15.

227. Ballantyne CM, Weiss R, Moccetti T, Vogt A, Eber B, Sosef F, et al. Efficacy and safety of rosuvastatin $40 \mathrm{mg}$ alone or in combination with ezetimibe in patients at high risk of cardiovascular disease (results from the EXPLORER study). Am J Cardiol. 2007;99(5):673-80.

228. Sabatine MS, Giugliano RP, Keech AC, Honarpour N, Wiviott SD, Murphy SA, et al. Evolocumab and Clinical Outcomes in Patients with Cardiovascular Disease. N Engl J Med. 2017;376(18):1713-22. 


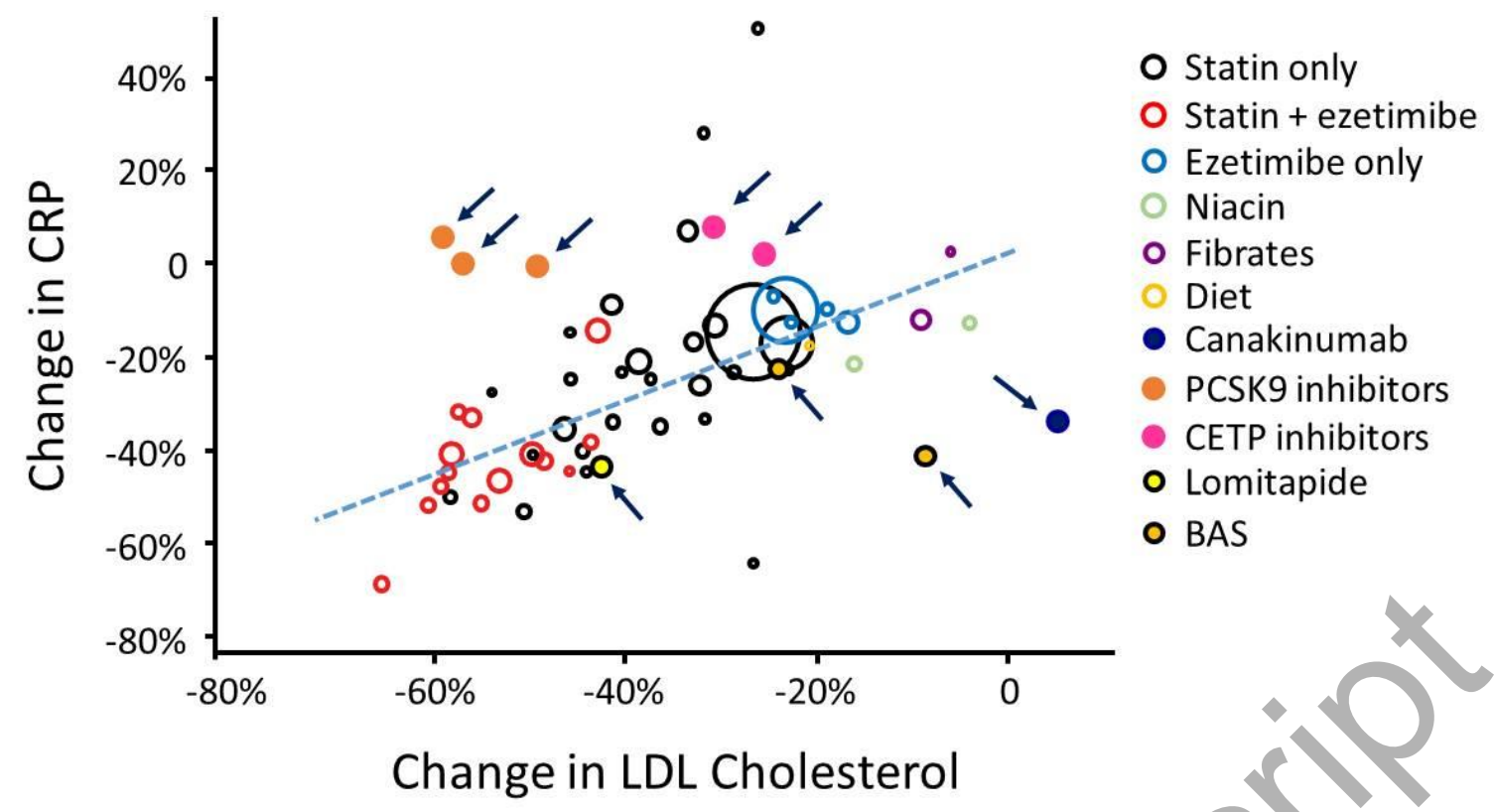

Figure 2

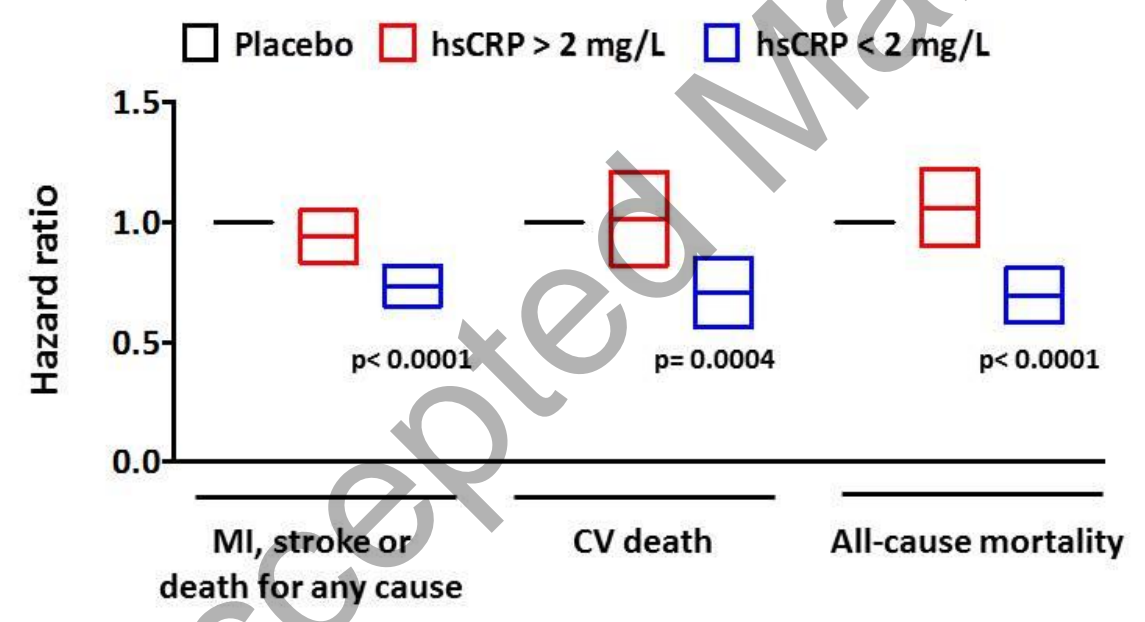

